\title{
Evaluación de redes tecnocientíficas: la red española sobre Áreas Protegidas, según la Web of Science.
}

\author{
José Pino-Díaz*, Evaristo Jiménez-Contreras ${ }^{\star *}$, Rosario Ruíz-Baños ${ }^{\star *}$, \\ Rafael Bailón-Moreno ${ }^{\star \star \star}$
}

Resumen: Las relaciones de coocurrencia entre las palabras clave, los investigadores y las revistas en los artículos científicos de un dominio documental concreto configuran una red tecnocientífica que puede ser analizada y cartografiada para conocer los nodos, subredes y áreas de investigación estratégicas, relevantes o importantes. Se ha realizado el análisis estratégico y el análisis dinámico, de traducción o de cambio, de la Red de Investigación Española sobre Áreas Protegidas según la Web of Science en el período 1981-2005. Producto de este análisis se han obtenido el Diagrama Estratégico y el Mapa de Conocimiento Estratégico de la Red Tecnocientífica o Mapa CERT, los listados de investigadores y de revistas de importancia estratégica y la tabla de análisis de actividad de las subredes. La red tecnocientífica analizada es una red bien estructurada, en la que se han identificado veintidós subredes estratégicas de investigación. El análisis de las redes tecnocientíficas mediante técnicas de creación de nuevo conocimiento a partir de bases de datos bibliográficas y de ingeniería y cartografía del conocimiento supone un apoyo de primer orden a la toma de decisiones estratégicas en Política Científica y en evaluación de la Ciencia y de la Tecnología.

Palabras clave: Redes científicas y tecnológicas, áreas protegidas, espacios naturales protegidos, parques nacionales, parques naturales, vigilancia estratégica científica y tecnológica, sistemas de conocimiento, gestión del conocimiento, evaluación de la actividad científica y técnica, cartografía de la información, cartografía del conocimiento, mapas de conocimiento estratégico de las redes tecnocientíficas, mapas CERT.

\section{Evaluation of techno-scientific networks: a Spanish network on protected areas, according to the Web of Science}

Abstract: Relationships of co-occurrence between keywords, researchers and journals in the professional literature of a given domain can be analyzed and mapped to discover

*Departamento de Filología Griega, Estudios Árabes, Lingüística General y Documentación. Universidad de Málaga.

**:Departamento de Biblioteconomía y Documentación. Universidad de Granada.

***:Departamento de Ingeniería Química. Universidad de Granada. Correo-e: jpinod@uma.es; evaristo@ugr.es; rruizb@ugr.es; bailonm@ugr.es.

Recibido: 06-10-2010; $2 .{ }^{\mathrm{a}}$ versión: 03-02-2011; aceptado: 14-02-2011. 
their nodes, subnets, and strategic research areas. A strategic and dynamic analysis was done of the Spanish Research Network on Protected Areas from 1981 to 2005, as identified by the Web of Science. This analysis has resulted in a Strategic Diagram and a Strategic Knowledge Map of Techno-scientific Network or CERT Map, lists of researchers and journals of strategic importance, and a table analyzing the activity of the subnets. The techno-scientific network is well-structured, with twenty-two strategic subnets. Network analysis using KDD techniques and engineering and knowledge mapping provides top grade support for strategic decision-making in science policy and the evaluation of science and technology.

Keywords: Scientific and technological networks, protected areas; national parks, knowledge managemen,; scientific and technological evaluation, knowledge discovery in database, KDD, information mapping, knowledge mapping, mapping strategic research networks, strategic knowledge maps of techno-scientific network, CERT maps.

\section{Introducción}

La evaluación de redes de conocimiento científico y tecnológico es una línea de investigación desarrollada a partir de la teoría sociológica de generación de conocimiento científico Actor-Red. En ella confluyen distintas disciplinas: creación de nuevo conocimiento a partir de los documentos de las bases de datos (knowledge discovery in databases, KDD), ingeniería del conocimiento y visualización de la información. En la actualidad la evaluación de redes de conocimiento se beneficia de la existencia de sistemas informáticos desarrollados para transformar la información en conocimiento (Polanco, 2008), procesando de una manera rápida y controlada ingentes conjuntos documentales y creando nuevo conocimiento a partir de ellos. Los sistemas de conocimiento son de gran utilidad para los equipos de inteligencia competitiva y de vigilancia tecnológica de las organizaciones ya que proporcionan informes, diagramas, gráficos y mapas muy apreciados en la toma de decisiones estratégicas. Este modus operandi, ya habitual en las grandes organizaciones empresariales, es apenas empleado en la actualidad en el campo de actividad de la vigilancia estratégica científica y tecnológica (VECT) de los órganos administrativos encargados de evaluar y diseñar las políticas científicas.

La Teoría Actor-Red, teoría sociológica sobre la Ciencia y la Tecnología en su concepción más ortodoxa describe la producción de conocimiento científico como resultado de las relaciones que se establecen entre los actores humanos (científicos, tecnólogos, gestores, etc.) y no humanos (centros de investigación, revistas, descriptores, patentes, etc.) (Callon y otros, 1986) (Callon, 1989) (Courtial, 1999). Bruno Latour, uno de los principales impulsores de esta teoría, la define como Sociología de las Relaciones (Latour, 2005). Así cualquier red de la Tecnociencia (Latour, 1983) está formada por un conjunto de actores y un conjunto de relaciones establecidas entre ellos en un período temporal concreto. Con el tiempo los actores y las relaciones cambian y dan lugar a nuevas redes y así se suceden 
unos a otros a lo largo del período de análisis. Esta teoría también llamada Sociología de la Traducción (entendida traducción como conversión, transformación, variación o cambio), estudia los cambios que se producen en las redes de conocimiento tecnocientífico. Estos cambios en las relaciones entre los actores tienen como consecuencia la aparición, el fortalecimiento, el equilibrio, el debilitamiento y la desaparición de actores en las redes (Ruíz-Baños, 1999). En el presente trabajo se emplea el concepto de "red tecnocientífica" tal como fue planteado por Latour en 1983, es decir, como la forma abreviada de "red de ciencia y tecnología".

La Teoría Actor-Red es útil para describir las complejas relaciones que se establecen en las redes de la Ciencia y la Tecnología, así como las de la Tecnociencia (Echevarría y González, 2009), entendida ésta como una modalidad de la actividad científica y tecnológica fruto de la hibridación entre Ciencia y Tecnología.

El Análisis de Palabras Asociadas (Michelet, 1988) (Courtial y Michelet, 1990) es una metodología que permite estudiar las redes tecnocíentíficas en base a las relaciones de coocurrencia producidas entre las palabras en los documentos, las cuales pueden ser nombres de investigadores, palabras clave, títulos de revistas científicas y/o centros de investigación (actores humanos y no humanos de la Teoría Actor-Red).

La Teoría de Grafos permite realizar una aproximación geométrica y visual a las redes tecnocientíficas, de manera que en el grafo de la red los actores pasan a ser los nodos y las relaciones entre los actores los enlaces entre los nodos. Para el trazado de grafos se han desarrollado diferentes algoritmos; entre ellos se encuentran los llamados algoritmos dirigidos por fuerzas, que tratan de modelizar el grafo como un sistema físico y buscan el equilibrio del mismo (Aiello y Silveira, 2004). En este sistema físico los nodos se posicionan como resultado del conjunto de fuerzas de atracción-repulsión existentes entre ellos (los nodos relacionados se atraen, los no conectados se repelen).

Los sistemas de conocimiento son sistemas informáticos ideados para estudiar y representar el conocimiento que los investigadores producen y difunden a través de sus documentos con el objetivo de crear nuevo conocimiento útil para la toma de decisiones, la definición de estrategias y la evaluación del estado de la ciencia y la tecnología a un momento dado (Polanco, 1997). Siguen el proceso KDD en sus diferentes fases y tienen su origen en los softwares cienciométricos desarrollados para facilitar el análisis de grandes conjuntos documentales (Larreina y otros, 2006). Copalred® (Bailón-Moreno, 2003) es un sistema de conocimiento basado en el análisis de palabras asociadas, que tiene su antecedente en Leximappe ${ }^{\circledR}$, software desarrollado por Whittaker, Law, Courtial y Bauin (Law y otros, 1988) (Law y Whittaker, 1992). Leximappe ${ }^{\circledR}$ se ha mostrado útil en el análisis estratégico de las redes de conocimiento científico y técnico (Callon y otros, 1991) (Ruíz-Baños, 1996). Leximappe ${ }^{\circledR}$ y Copalred ${ }^{\circledR}$ han sido empleados en el estudio de grandes conjuntos documentales de diferentes disciplinas académicas: Arqueología (Ruíz-Baños, 1997), Ingeniería Química (Jurado-Alameda y otros, 2002a) (Jurado-Alameda y otros, 2002b) (Bailón-Moreno y otros, 2006) o Fisioterapia (García-Ríos, 2009). 
La visualización de información textual mediante mapas cartográficos realizados con Sistemas de Información Geográfica (SIG), softwares desarrollados para representar información espacial, es propuesta por Old (2001). Pino-Díaz y otros (2009) realizan mapas cartográficos de dos y tres dimensiones de redes tecnocientíficas a partir de las coordenadas de los nodos de los grafos de las redes. Ambas técnicas utilizan la metáfora visual del paisaje para visualizar datos no espaciales.

El objetivo de este trabajo es realizar el análisis estratégico y dinámico de la Red Española de Investigación sobre Áreas Protegidas, según la Web of Science, en el período 1981-2005, mediante el empleo del sistema de conocimiento Copalred®, el software de análisis de redes Pajek ${ }^{\circledR}$ y el SIG ArcView ${ }^{\circledR}$. Fruto del análisis se van a obtener el diagrama estratégico, los listados de investigadores y de revistas estratégicas y los grafos y mapas de conocimiento estratégico de la red tecnocientífica. Los resultados obtenidos van a constituir elementos de apoyo de gran valor e interés para la evaluación científica y tecnológica de la red estudiada y para la toma de decisiones estratégicas en el ámbito de la Gestión y Administración de los Espacios Naturales Protegidos (Parques Nacionales, Parques Naturales, Reservas Naturales, etc.) en España.

\section{Metodología}

Se ha elegido como base de datos fuente la Web of Science de Thomson Reuters. Se han seleccionado los artículos sobre Áreas Protegidas (búsqueda en los campos de title, abstract, author-keyword y keyword Plus de los términos: natural reserve o natural preserve o national park o natural park o protected area o protected natural area, tanto singulares como plurales), del período 1981-2005, provenientes de España, en SCI expanded, SSCI y Arts and Humanities.

El conjunto documental se ha procesado con el sistema de conocimiento Copalred® (Bailón-Moreno, 2003). Este sistema de conocimiento permite realizar el control de autoridades como fase previa a la creación de los vocabularios maestros; se ha realizado el control de las palabras clave, los autores y los títulos de revistas.

Se ha realizado el análisis estratégico de todo el conjunto documental para el período 1981-2005. Para realizar el análisis dinámico se ha dividido el período general de 25 años en cinco periodos de cinco años cada uno; se han obtenido las subredes de cada período y las traducciones o cambios producidos a lo largo de los cinco periodos entre las subredes y entre los términos de dichas subredes.

Se ha preparado para cada registro un nuevo campo formado por las palabras clave, los autores y la revista (al que se ha denominado campo PCAR), y se han estudiado las ocurrencias y coocurrencias de los distintos términos en dicho campo.

Se han fijado en el sistema de conocimiento los umbrales de cálculo siguientes: número mínimo de ocurrencias de cada término igual a cinco $\left(\operatorname{cmin}_{i}=5\right)$ y nú- 
mero mínimo de coocurrencias entre pares de términos igual a tres $\left(\mathrm{cmin}_{i j}=3\right)$. El índice de equivalencia o índice de asociación entre términos se ha calculado de acuerdo a la expresión matemática $\left(e_{i j}=c_{i j}^{2} / c_{i} \times c_{j}\right)$.

Se han obtenido tres listados de valores alfanuméricos: el listado de nodos cuya ocurrencia es igual o mayor a cinco $\left(c_{i}\right)$, el listado de pares de nodos cuya coocurrencia es igual o mayor a tres $\left(c_{i j}\right)$ y el listado de índices de equivalencia o índices de asociación entre los pares de términos $\left(e_{i j}\right)$.

Para citar a la Red de Investigación sobre Áreas Protegidas según la Web of Science se ha empleado la expresión abreviada Red WOS PCAR 53210 (19812005), que incluye la procedencia de las bases de datos fuente (WOS), seguida del nombre del campo de análisis (PCAR), seguido del número que indica el análisis realizado en el sistema de conocimiento (53210, que indica que la mínima ocurrencia de los términos elegida es 5, que la mínima coocurrencia entre pares de términos elegida es 3, y que el tamaño elegido para las subredes puede variar entre un mínimo de 2 y un máximo de 10 términos o nodos) y por último el período de estudio (1981-2005).

Se puede considerar el grafo de una red tecnocientífica como un sistema físico que puede ser modelizado mediante el algoritmo de Kamada y Kawai (1989) para que adopte una posición de mínima energía. A consecuencia de ello, y una vez asignados a los enlaces los valores de sus índices de equivalencia o índices de asociación, los términos o nodos unidos por los enlaces de mayor valor aparecen próximos, constituyendo agrupaciones o subredes que pueden ser identificadas en el grafo de la red. Igualmente, las subredes entre sí también se posicionan en la red formando agrupaciones, a las que se les ha denominado "áreas de investigación".

Los listados obtenidos se han analizado y visualizado con el software de análisis de redes Pajek ${ }^{\circledR}$ (Batagelj y Mrvar, sf), tomando como algoritmo de visualización Kamada-Kawai y como opciones de dibujo del grafo, "los valores de las líneas son similitudes" y "líneas de diferente ancho" (el valor de cada enlace o línea se corresponde con su índice de equivalencia).

Se ha dibujado el grafo de la red y se han separado componentes; a continuación se han realizado sucesivas eliminaciones de los enlaces débiles en orden creciente de su índice de equivalencia hasta obtener grupos o subredes con un número de nodos igual o inferior a 10; así ha resultado que el valor mínimo de los enlaces que han permanecido sin eliminar ha quedado fijado en 1819 (el índice de equivalencia adquiere valores entre 0, ausencia de relación, y 10.000, relación plena). Por último, las áreas estratégicas de investigación se han obtenido gráficamente agrupando las subredes conectadas por algún enlace (independientemente del valor de éste).

Con este método gráfico de visualización de las subredes se obtienen resultados similares a los que se obtendrían en un sistema de conocimiento mediante el empleo del algoritmo de clasificación por enlace simple.

A partir de las coordenadas de los nodos en el grafo del componente principal se ha calculado su isobaricentro, al que se le ha denominado Centroide de 
la Red. Se ha obtenido la centralidad de cada nodo, también denominada centralidad nodal, de la diferencia entre la unidad y la distancia euclídea del nodo al Centroide (a mayor distancia euclídea del centroide, menor centralidad nodal).

Para realizar el Diagrama Estratégico de la red se han obtenido previamente los valores de la centralidad y densidad medias normalizadas de las subredes. La centralidad media normalizada de una subred se ha calculado como media de los valores de centralidad de los términos o nodos que la componen (normalizados respecto al valor más elevado de centralidad nodal del conjunto de nodos de la red). La densidad media normalizada de la subred se ha calculado como la media de los valores de sus enlaces (normalizada respecto al valor más elevado de densidad de subred del conjunto de subredes de la red).

Los mapas cartográficos se han realizado mediante el SIG ArcView ${ }^{\circledR}$ 3.2. Como coordenadas $(x, y)$ de los términos en los mapas se han tomado las coordenadas $(x, y)$ de los términos o nodos en el componente principal del grafo y como coordenada $(z)$ se han tomado los valores de la importancia absoluta de los términos de la red. Se ha definido el concepto de "importancia absoluta de un término en la red tecnocientífica" como la suma de sus valores de centralidad nodal normalizado y de densidad media normalizada de la subred a la que pertenece.

En estos mapas cartográficos se visualiza en planimetría la proximidad entre los términos y la proximidad al Centroide (centralidad nodal). La mayor o menor proximidad de los términos, de las subredes o de las áreas de investigación al Centroide de la red indica su mayor o menor grado de relación con la temática general del estudio (la investigación sobre áreas protegidas en España). En altimetría, la altitud de cada término indica su importancia absoluta en el conjunto de la red. El SIG permite, además, obtener imágenes de la red en tres dimensiones, lo cual facilita la interpretación de los mapas.

Se ha definido el concepto de importancia estratégica de un término en la red tecnocientífica" como la característica que toma el término por su pertenencia a una subred tipificada estratégicamente de un modo u otro según haya sido clasificada en uno de los cuatro cuadrantes del diagrama estratégico de la red.

Se ha denominado Mapa de Importancia Estratégica de la Red Tecnocientífica (Mapa I-VECT) el mapa cartográfico al que se ha trasladado la información del Diagrama Estratégico de la Red. En el mapa se indica mediante símbolos de diferente forma y color si los términos pertenecen a subredes de investigación del primer (subredes motor de investigación), segundo (subredes puente o categorizaciones), tercer (subredes especializadas o metodologías) o cuarto cuadrante (subredes nacientes o en destrucción).

\section{Resultados}

El conjunto documental de artículos sobre áreas protegidas de la Web of Science publicados entre 1981 y 2005 y procedentes de España se compone de 560 registros en los que aparecen 1961 palabras clave, 1316 investigadores y 249 
revistas. Las Revistas con un número de ocurrencias igual o mayor a cinco (número mínimo de ocurrencias fijado para realizar el análisis con el sistema de conocimiento Copalred $\AA$ ) se pueden observar en la tabla I. Los Autores de la base de datos documental con cinco o más ocurrencias se muestran en la tabla II.

\section{TABLA I}

Ranking de revistas de la base de conocimiento española sobre Áreas Protegidas de la Web of Science (1981-2005) (número de ocurrencias igual o mayor a cinco)

\begin{tabular}{|c|c|c|c|c|c|}
\hline Rango & Ocu & Revista & Rango & Ocu & Revista \\
\hline 1 & 38 & Biological Conservation & 13 & 6 & Journal of Applied Ecology \\
\hline 2 & 17 & Hydrobiologia & 14 & 6 & Environmental Pollution \\
\hline 3 & 13 & $\begin{array}{l}\text { Science of the Total Envi- } \\
\text { ronment }\end{array}$ & 15 & 6 & Conservation Biology \\
\hline 4 & 12 & $\begin{array}{l}\text { Biodiversity and Conser- } \\
\text { vation }\end{array}$ & 16 & 6 & $\begin{array}{l}\text { Bulletin of Environmental } \\
\text { Contamination }\end{array}$ \\
\hline 5 & 11 & Journal of Zoology & 17 & 5 & Marine Biology \\
\hline 6 & 7 & Wetlands & 18 & 5 & Mammalia \\
\hline 7 & 7 & $\begin{array}{l}\text { Marine Ecology-Progress } \\
\text { Series }\end{array}$ & 19 & 5 & $\begin{array}{l}\text { International Journal of En- } \\
\text { vironmental Analytical }\end{array}$ \\
\hline 8 & 7 & Landscape Ecology & 20 & 5 & Ibis \\
\hline 9 & 7 & $\begin{array}{l}\text { Journal of Vegetation Scien- } \\
\quad c e\end{array}$ & 21 & 5 & $\begin{array}{l}\text { Forest Ecology and Mana- } \\
\text { gement }\end{array}$ \\
\hline 10 & 7 & $\begin{array}{l}\text { Journal of Arid Environ- } \\
\text { ments }\end{array}$ & 22 & 5 & Environmental Geology \\
\hline 11 & 6 & Journal of Wildlife Diseases & 23 & 5 & Cryptogamie Mycologie \\
\hline 12 & 6 & $\begin{array}{l}\text { Journal of Environmental } \\
\text { Management }\end{array}$ & 24 & 5 & Acta Theriologica \\
\hline
\end{tabular}

\section{Red de Investigación WOS PCAR 53210 (1981-2005)}

La Red WOS PCAR 53210 (1981-2005) está formada por 235 nodos o términos, cada uno con un número de ocurrencias igual o superior a cinco y por 573 enlaces entre los nodos (cada enlace con un valor de coocurrencia igual o mayor a tres). La red está formada por dos Componentes (no conexos entre sí), un Componente Principal (formado por 229 nodos) y uno Secundario (formado por seis nodos), al que se le ha denominado «Capa, M.». 


\section{TABLA II}

Ranking de autores de la base de conocimiento española sobre Áreas Protegidas de la Web of Science (1981-2005) (número de ocurrencias igual o mayor a cinco)

\begin{tabular}{|c|c|c|c|c|c|}
\hline Rango & Ocu & Autor & Rango & Ocu & Autor \\
\hline 1 & 32 & Delibes, M. & 28 & 6 & López, E. \\
\hline 2 & 22 & Palomares, F. & 29 & 6 & Gómez-Ariza, J. L. \\
\hline 3 & 17 & González, M. J. & 30 & 6 & Green, A. J. \\
\hline 4 & 16 & Ferrer, M. & 31 & 6 & García-Rubies, A. \\
\hline 5 & 14 & Hernández, L. M. & 32 & 6 & Fernández, N. \\
\hline 6 & 11 & Serrano, L. & 33 & 6 & Fedriani, J. M. \\
\hline 7 & 10 & Revilla, E. & 34 & 6 & Clemente, L. E. \\
\hline 8 & 10 & Hiraldo, F. & 35 & 6 & Capa, M. \\
\hline 9 & 10 & Ferreras, P. & 36 & 6 & Braza, F. \\
\hline 10 & 9 & Toja, J. & 37 & 6 & Beltran, J. F. \\
\hline 11 & 9 & Pérez, J. M. & 38 & 6 & Baos, R. \\
\hline 12 & 9 & Novo, F. G. & 39 & 6 & Angeler, D. G. \\
\hline 13 & 9 & Moreno, S. & 40 & 5 & Travaini, A. \\
\hline 14 & 9 & Fernández, M. A. & 41 & 5 & Rojo, C. \\
\hline 15 & 9 & Alvarez-Cobelas, M. & 42 & 5 & Rodrigo, M. A. \\
\hline 16 & 8 & Zabala, M. & 43 & 5 & Querol, X. \\
\hline 17 & 8 & Villafuerte, R. & 44 & 5 & Muñoz-Reinoso, J. C. \\
\hline 18 & 8 & Sala, E. & 45 & 5 & Moreno, G. \\
\hline 19 & 8 & Granados, J. E. & 46 & 5 & Montoro, R. \\
\hline 20 & 8 & Barradas, M. C. D. & 47 & 5 & LLoret, F. \\
\hline 21 & 7 & Zunzunegui, M. & 48 & 5 & Del Valls, T. A. \\
\hline 22 & 7 & Sánchez-Carrillo, S. & 49 & 5 & Bermejo, M. \\
\hline 23 & 7 & San Martín, G. & 50 & 5 & Baluja, G. \\
\hline 24 & 6 & Soriguer, R. C. & 51 & 5 & Balbontin, J. \\
\hline 25 & 6 & Ruíz-Martínez, I. & 52 & 5 & Aldama, J. J. \\
\hline 26 & 6 & Rico, M. C. & 53 & 5 & Aguado, M. T. \\
\hline 27 & 6 & Montes, C. & & & \\
\hline
\end{tabular}




\section{Subredes Estratégicas de Investigación}

Se han obtenido veintidos subredes estratégicas de la Red WOS PCAR (veintiuna subredes del Componente Principal y una subred del Componente Secundario).

El Diagrama Estratégico obtenido es el que se representa en la figura 1. La posición de las subredes en cada cuadrante es la siguiente:

\section{FIGURA 1}

Diagrama Estratégico de la Red WOS_PCAR_53210 (1981-2005) (véase nota 2)

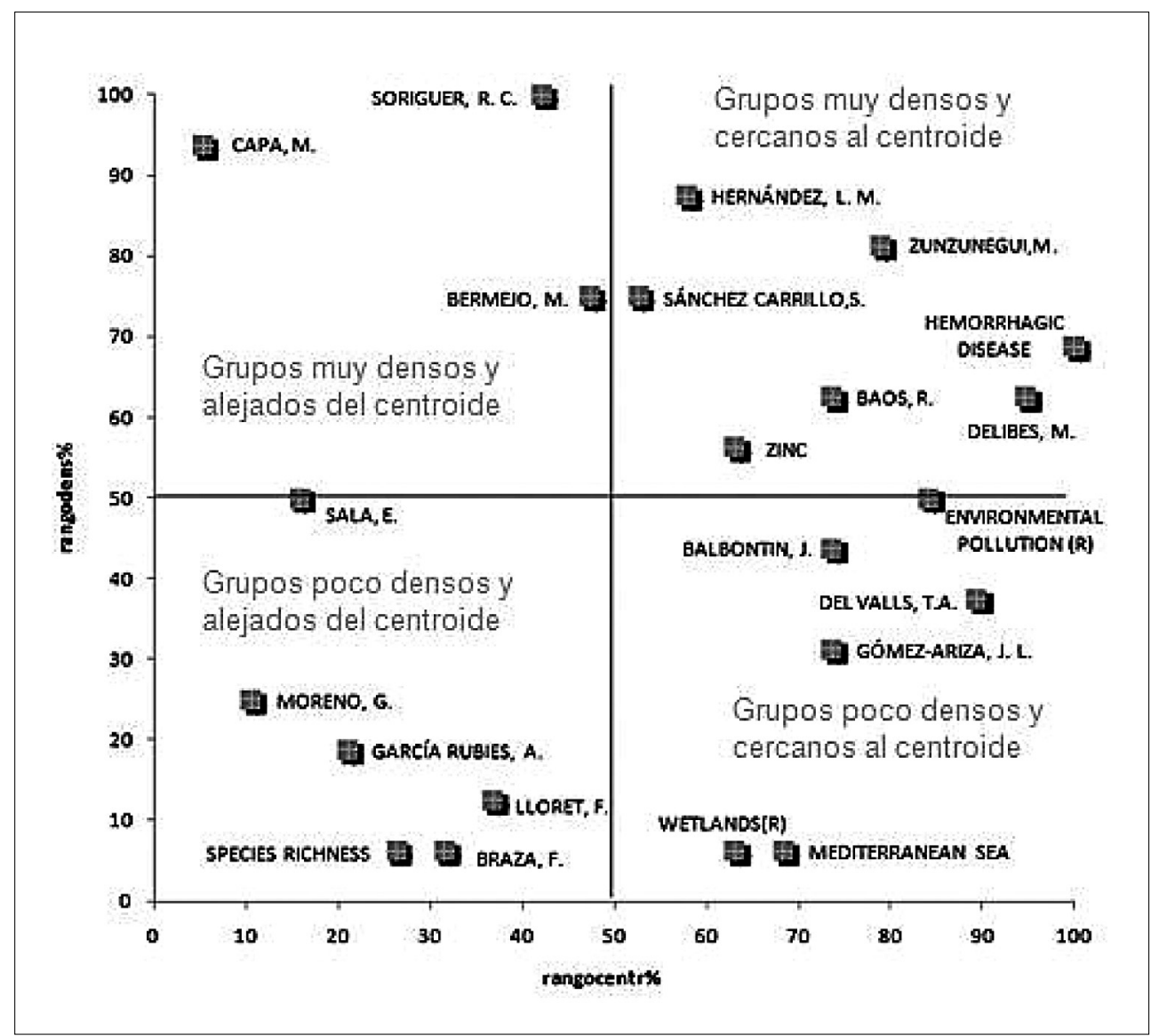

Subredes (en negrita) del cuadrante n. ${ }^{\circ} 1$ y términos o nodos (incluídos entre paréntesis) que las forman. Se trata de las subredes próximas al objeto de estudio y con nodos muy bien relacionados internamente, también denominadas subredes motor de investigación; subredes centrales y muy densas. 
- Hemorrhagic disease ("Villafuerte, R.”, "Moreno, S.”, Oryctolagus cuniculus y hemorragic disease).

- "Delibes, M.» ("Delibes, M.", Linx pardinus, "Revilla, E.", "Palomares, F.", "Ferreras, J. M.", "Fedriani, J. M.", "Aldama, J. J." y "Beltrán, J. F.").

- «Zunzunegui, M.» ("Zunzunegui, M.”, "Barradas, M. C. D.», shrubs y «Novo, F. G.").

- «Baos, R.» ("Hiraldo, F.”, "Baos, R.», «Montoro, R.» y arsenic).

- Zinc (cadmio, Pb, zinc, copper y soils).

- «Hernández, L. M.», (Baluja, G.», "Rico, M. C.», "Hernández, L. M.”, "González, M. J.", "Fernández, M. A.» y Bulletin of Environmental Contamination and Toxicology-R).

- "Sánchez Carrillo, S.» ("Angeler, D. G.», "Sánchez Carrillo, S.», "Alvarez Cobelas, M.", "Rodrigo, M. A.", "Rojo, C." y Phytoplankton).

Subredes del cuadrante n. ${ }^{\circ} 2$ y nodos que las forman. Son las subredes próximas al objeto de estudio pero con nodos relacionados débilmente; subredes centrales pero poco densas.

- Environmental pollution (revista) (contamination, Environmental Pollution-R).

- «Del Valls, T. A.» (Guadalquivir Estuary, Aznalcóllar mine toxic spill, pollution, Guadiamar River, SW-Spain, "Del Valls, T. A.", heavy metals, Science of the Total Environment-R y Doñana National Park).

- «Balbontín, J.» ("Balbontín, J.", Aquila adalberti, age y "Ferrer, M.»).

- «Gómez Ariza, J. L.» (Gómez Ariza, J. L.” y sequential extraccion).

- Mediterranean Sea (Mediterranean Sea y marine protected areas).

- Wetlands (revista) (Lakes y Wetlands-R).

Subredes del cuadrante n. 3 y nodos que las forman. Son las subredes alejadas del objeto de estudio pero con relaciones intensas entre los términos que las forman; son subredes periféricas pero muy densas.

- «Bermejo, M.» ("Bermejo, M.» y Gorilla gorilla)

- "Soriguer, R.C.» ("Soriguer, R.C.”, "Granados J.E.”, y "Pérez, J.M.”, "Ruíz Martínez, I." y Sierra Nevada National Park) y

- «Capa, M.» (“Capa, M.», "López, E.», "Sanmartín, G.», Shyllidae, Polychaeta y Panamá)

Subredes del cuadrante n. ${ }^{\circ} 4$ y nodos que las forman. Subredes alejadas del objeto del estudio y con relaciones débiles entre sus términos; son subredes periféricas y poco densas.

- «Lloret, F.» (fire, "Lloret, F." y Yellowstone National Park).

- «Braza, F.» (Braza, F.» y Cervus elaphus). 
- Species richness (diversity y species richnees).

- "García Rubies, A.» (García Rubies, A.”, marine reserves y assemblages).

- "Sala, E.» (coral reefs, "Zabala, M.”, "Sala, E.», Marine Biology-R y populations structure).

- «Moreno, G.», ("Moreno, G.» y Cryptogamie Mycologie-R).

\section{Áreas Estratégicas de Investigación}

El Componente Principal de la Red WOS PCAR (1981-2005) consta de nueve áreas estratégicas de investigación (véase figura 2, en ésta figura sólo aparecen las áreas estratégicas del Componente Principal):

\section{FIGURA 2}

Áreas estratégicas de investigación del Componente Principal de la Red WOS_PCAR_53210 (1981-2005) (véase nota 3)

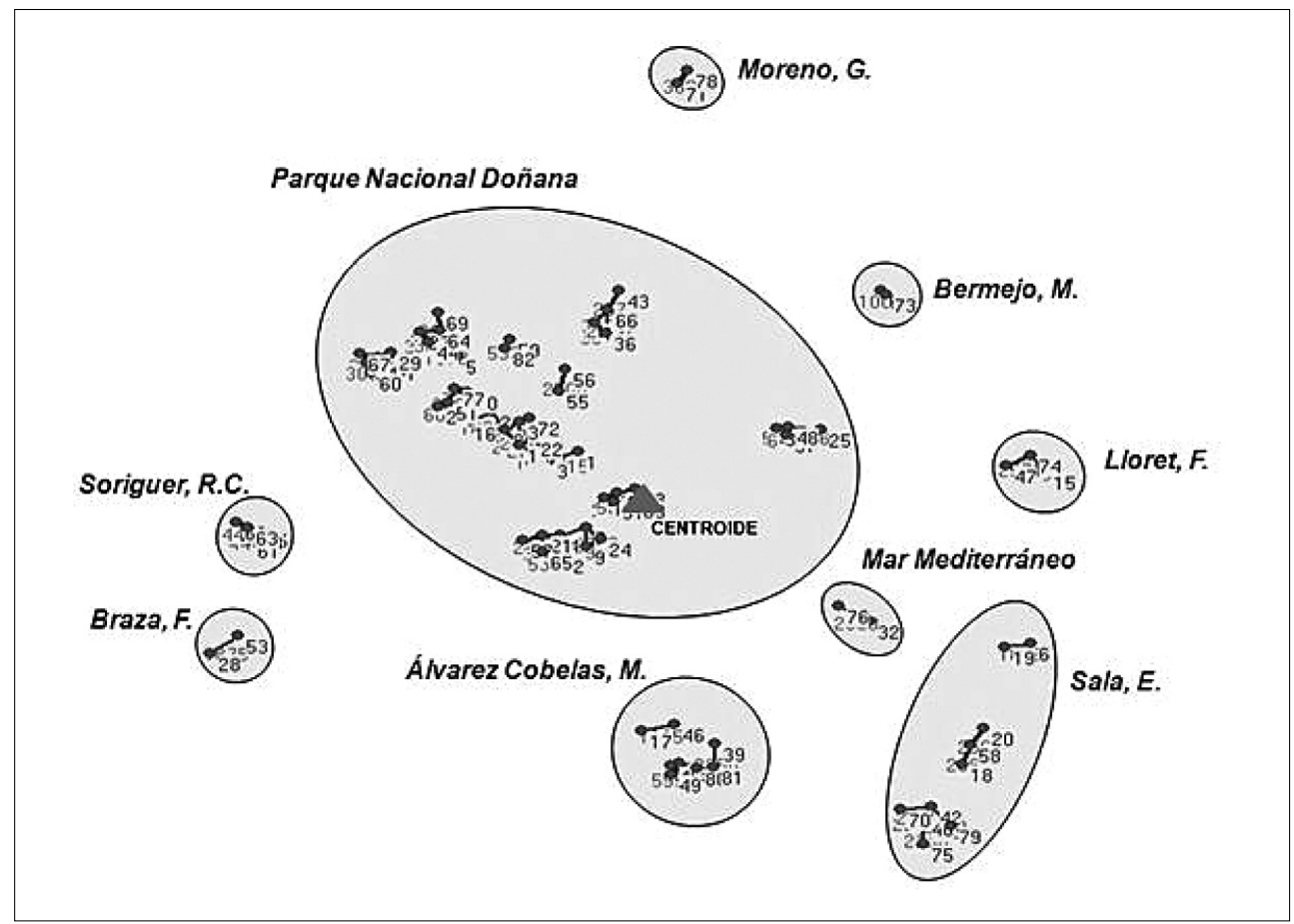

1. Parque Nacional de Doñana.

2. "Álvarez Cobelas, M.".

3. "Sala, E.".

4. "Soriguer, R.C".

5. Mar Mediterráneo. 
6. "Moreno, G.".

7. "Bermejo, M.".

8. "Lloret, F.".

9. "Braza, F.".

1. Área de Investigación "Parque Nacional de Doñana". Esta área estratégica de investigación tiene 10 subredes: Hemorrhagic disease, "Delibes, M.", "Zunzunegui, M.», «Baos, R.», Zinc, «Hernández, L. M.», «Environmental Pollution-R», «Del Valls, T. A.», «Balbontín, J.» y «Gómez Ariza, J. L.»:

- Elementos singulares de investigación (agrupados y diferenciados por subred de pertenencia):

- Linx pardinus.

- Aquila adalberti y age.

- Orictolagus cuniculus y hemorrhagic disease.

- Shrubs.

- SW-Spain, Doñana National Park, heavy metals, pollution, Aznalcollar mine toxic spill, Guadalquivir Estuary y Guadiamar River.

- Contamination.

- Copper, zinc, cadmio, Pb y soils.

- Sequential extraction.

- Arsenic.

- Investigadores (agrupados y diferenciados por subred de pertenencia):

— «Delibes, M.”, «Ferreras, P.», “Aldama, J. J.”, «Beltrán, J. F.”, "Fedriani, J. M.”, "Palomares, F." y «Revilla, E.».

— "Ferrer, M." y "Balbotín, J.".

— "Villafuerte, R." y "Moreno, S.".

— "Zunzunegui, J. M.", "Barradas, M. N." y "Novo, F. G.».

- "Del Valls, T. A.".

— "Rico, M. C.", "Baluja, G.», "Hernández, L. M.», "Fernández, M. A.” y "González, M. J.".

- "Gómez Ariza, J. L.".

— "Baos, R.», "Montoro, R.» y "Hiraldo, F.".

- Centros de Investigación (obtenidos de los artículos que corresponden a la área):

- Consejo Superior de Investigaciones Científicas (CSIC), Estación Biológica de Doñana

- Universidad de Cádiz, Facultad de Ciencias del Mar, Departamento de Química Física.

- Universidad de Sevilla, Facultad de Biología, Departamento de Biología Vegetal y Ecología. 
- CSIC, Instituto de Química Orgánica, Departamento de Contaminación Ambiental.

- Universidad de Huelva, Facultad de Ciencias Experimentales.

- Revistas en las subredes:

- Bulletin of Environmental Contamination and Toxicology.

- Environmental Pollution.

- Science of the Total Environment.

2. Área de Investigación "Álvarez Cobelas M.". Esta área está formada por dos subredes «Sánchez Carrillo, S.» y «Wetlands (revista)»:

- Elementos singulares de investigación (diferenciados por subred de pertenencia):

- Phytoplankton.

- Lakes.

- Investigadores:

— "Rojo, C.», "Rodrigo, M. A.», "Álvarez Cobelas, M.», "Sánchez Carrillo, S." y "Angeler, D. G.".

- Centros de Investigación:

- CSIC, Centro de Ciencias Medioambientales.

- Universidad de Valencia, Instituto Cavanilles de Biodiversidad y Biología Evolutiva.

- Revista de la Área:

- Wetlands-R.

3. Área Estratégica de Investigación "Sala, E.". Esta área está formada por tres subredes "Sala, E.", "García Rubies, A.» y Species richness:

- Elementos singulares de investigación (agrupados y diferenciados según subred de pertenencia):

- Marine reserves y assemblages.

- Population structure y coral reefs.

- Diversity y species richness.

- Investigadores (diferenciados según subred de pertenencia):

— "García Rubies, A.".

— "Sala, E." y "Zabala, M.».

- Revista de la Área:

- Marine Biology. 
- Centros de Investigación:

- CSIC, Centro de Estudios Avanzados de Blanes.

- Universidad de Barcelona, Facultad de Biología, Departamento de Ecología.

- Universidad de las Islas Baleares, Laboratorio de Biología Marina.

4. Área de Investigación "Soriguer, R. C.":

- Elemento singular de investigación:

- Sierra Nevada National Park.

- Investigadores:

— "Ruíz Martínez, I.», "Soriguer, R. C.», "Pérez, J. M.» y “Granados, J. E.».

- Centros de Investigación:

- CSIC, Estación Biológica de Doñana.

- Universidad de Jaén, Facultad de Ciencias Experimentales, Departamento Animales y Plantas, Biología y Ecología.

- Empresa de Gestión Medioambiental (Consejería de Medio Ambiente, Junta de Andalucía).

5. Área de Investigación "Mar Mediterráneo":

- Elementos singulares de investigación:

- Mediterranean Sea y marine protected areas.

- Centros de Investigación:

- CSIC, Centro de Estudios Avanzados de Blanes.

- Universidad de Alicante, Departamento de Ciencias Ambientales y Recursos Naturales, Unidad de Biología Marina.

- Universidad de Las Palmas, Facultad de Ciencias del Mar, Departamento de Biología.

- Instituto Español de Oceanografía.

- CSIC, Instituto de Ciencias del Mar.

- Universidad de Barcelona, Departamento de Ecología.

6. Área de Investigación "Moreno, G.":

- Investigador:

- «Moreno, G.».

- Centro de Investigación:

- Universidad de Alcalá de Henares, Departamento de Biología Vegetal. 
- Revista:

- Crytogamie Mycologie.

7. Área de Investigación "Bermejo, M.»:

- Elemento singular de investigación:

- Gorilla gorilla.

- Investigadora:

- "Bermejo, M."

- Centro de Investigación:

- Universidad de Barcelona, Facultad de Biología, Departamento de Biología Animal, Vertebrados.

8. Área de Investigación "Lloret, F.»:

- Elemento singular de investigación:

- Fire y Yellowstone National Park.

- Investigador:

— «LLoret, F.».

- Centro de Investigación:

- Universidad Autónoma de Barcelona, Centro de Investigaciones Ecológicas y de Aplicaciones Forestales.

9. Área de Investigación "Braza, F.»:

- Elemento singular de investigación:

- Cervus elaphus.

- Investigador:

— "Braza, F.".

- Centro de Investigación:

- CSIC, Estación Biológica de Doñana.

La subred «Capa, M.», única subred del Componente Secundario de la red, constituye en sí otra área estratégica de investigación, denominada igualmente "Capa, M." (esta área no aparece en la figura 2, grafo de las áreas estratégicas de investigación del Componente Principal): 
Área Estratégica de Investigación, "Capa, M.»:

- Elementos singulares de investigación:

- Syllidae, Polychaeta y Panama.

- Investigadores:

— "Capa, M.», "San Martín, G.” y “López, E.».

- Centro de Investigación:

- Universidad Autónoma de Madrid, Departamento de Biología y Zoología, Laboratorio de Biología Marina e Invertebrados.

La Área Estratégica de Investigación "Parque Nacional de Doñana" constituye el núcleo central de la Red Tecnocientífica Española de Investigación sobre Áreas Protegidas según la Web of Science. Es una área estratégica de investigación activa en los tres últimos periodos de estudio (1991-2005), formada por nueve subredes estratégicas que se sitúan en torno al Centroide de la red; cuatro encuadrables en el campo de las Ciencias de la Vida (Hemorrhagic disease, «Delibes, M.», "Zunzunegui, M.», «Baos, R.» $\mathbf{y}$ «Balbontín, J.») y cinco sobre contaminación ambiental (Zinc, «Hernández, L. M.», «Environmental Pollution-R», «Del Valls, T. A.» y "Gómez Ariza, J. L.»). La importancia de esta área se justifica en las investigaciones desarrolladas en el Parque Nacional de Doñana por investigadores de la Estación Biológica de Doñana, de las Universidades periféricas al área protegida [Universidad de Sevilla (Facultad de Biología, Departamento de Biología Vegetal y Ecología), Universidad de Cádiz (Facultad de Ciencias del Mar, Departamento de Química Física) y Universidad de Huelva (Facultad de Ciencias Experimentales)] y del Departamento de Contaminación Ambiental del Instituto de Química Orgánica (CSIC).

A la anterior le sigue en importancia la área estratégica "Álvarez Cobelas, M.", área activa en el último decenio de estudio (1996-2005), formada por dos subredes centrales (una densa y otra menos densa), dedicada al estudio de las zonas húmedas (lakes y phitoplankton) y constituída por investigadores del Centro de Ciencias Medioambientales del CSIC y del Instituto Cavanilles de Biodiversidad y Biología Evolutiva de la Universidad de Valencia, que han publicado preferentemente en la revista Wetlands.

Como tercera área relevante aparece "Sala, E.", área formada por tres subredes poco centrales y poco densas, con actividad investigadora sobre las reservas marinas y las poblaciones de peces asociadas a sus fondos. Está formada por investigadores del Centro de Estudios Avanzados de Blanes del CSIC, del Departamento de Ecología de la Facultad de Biología de la Universidad de Barcelona y del Laboratorio de Biología Marina de la Universidad de las Islas Baleares, que publican en la revista Marine Biology.

El resto de áreas estratégicas de investigación están constituídas por una sola subred. "Mediterranean Sea" es una subred generalista (subred central y poco 
densa) dedicada al estudio de las zonas marinas protegidas en el Mar mediterráneo. "Soriguer, $R$. C." es una subred adyacente (periférica y densa) dedicada al estudio de la especie "Capra pirenaica hispanica" en el Parque Nacional de Sierra Nevada. "Bermejo, $M$ " es una subred adyacente dedicada al estudio de la especie "Gorilla gorilla". "Capa, $M$ " es una subred adyacente dedicada al estudio de la familia Syllidae de la clase Polichaeta en el Parque Nacional de Coiba (Panamá). "Moreno, G." es una subred no consolidada plenamente (periférica y poco densa) dedicada a estudios criptogámicos y con publicación preferente en la revista Cryptogamie Mycologie. "Lloret, $F$." es una subred naciente (periférica y poco densa) dedicada al estudio de los incendios forestales. "Braza, F." es una subred en desaparición (periférica y poco densa) dedicada al estudio del Cervus elaphus.

\section{Mapa de Conocimiento Estratégico de la Red Tecnocientífica (Mapa CERT)}

El nuevo conocimiento obtenido del análisis estratégico de la red WOS PCAR (1981-2005) se ha trasladado a un conjunto de mapas cartográficos que se pueden visualizar en dos o tres dimensiones. En la figura 3 se puede observar una imagen 3D, con el centroide, y la leyenda del Mapa CERT realizado a partir de los términos del Componente Principal de la red.

\section{Análisis Dinámico de las Subredes de Investigación}

Además del análisis estratégico de la red, realizado para el período total de 25 años, se ha realizado el análisis dinámico de la red durante cinco periodos de cinco años (1. ${ }^{\circ}$ período, 1981-1985; 2..$^{\circ}$ período, 1986-1990; 3..$^{\circ}$ período, 1991 1995; 4. ${ }^{\circ}$ período, 1996-2000; y $5^{\circ}$ período, 2001-2005). De dicho análisis dinámico se deduce que la Red Española de Investigación sobre Áreas Protegidas es una red joven, de formación tardía, con subredes estratégicas de investigación en sólo los tres últimos periodos de estudio.

Se observa que la Red WOS PCAR 53210 (1981-2005) posee dos subredes en el período 1991-1995, trece en el período 1996-2000 y nueve en el período 20012005. No se detecta una continuidad en el tiempo de las diferentes subredes, tan solo la traducción «Populations» $\rightarrow$ «Conservation" desde el 1991 hasta el 2000 (3. ${ }^{\circ}$ y $4 .^{\circ}$ periodos); y las tres traducciones siguientes: «Delibes,M.» $\rightarrow$ «Palomares, F.»; «Patterns» $\rightarrow$ «Diversity» y «Succession» $\rightarrow$ «Succession», desde el 1996 hasta el 2005 ( $4 .^{\circ}$ y $5 .^{\circ}$ periodos).

"Delibes, M." es un término que forma parte de subredes estratégicas en los tres últimos periodos. Aparece en el período 1991-1995 asociado al término "Doñana National Park" de la subred "Doñana National Park"; da nombre a una subred completa de diez nodos en el período 1996-2000 (subred «Delibes, M.») y en el período 2001-2005, junto con los términos "Palomares, F." y "Lynx pardinus", forma parte de la subred «Palomares, F.», que le acompañan provenientes de la subred «Delibes, M.» del período anterior. 
FIGURA 3

Imagen 3D dle Mapa CERT de Investigadores de la red WOS_PCAR_53210 (1981-2005)

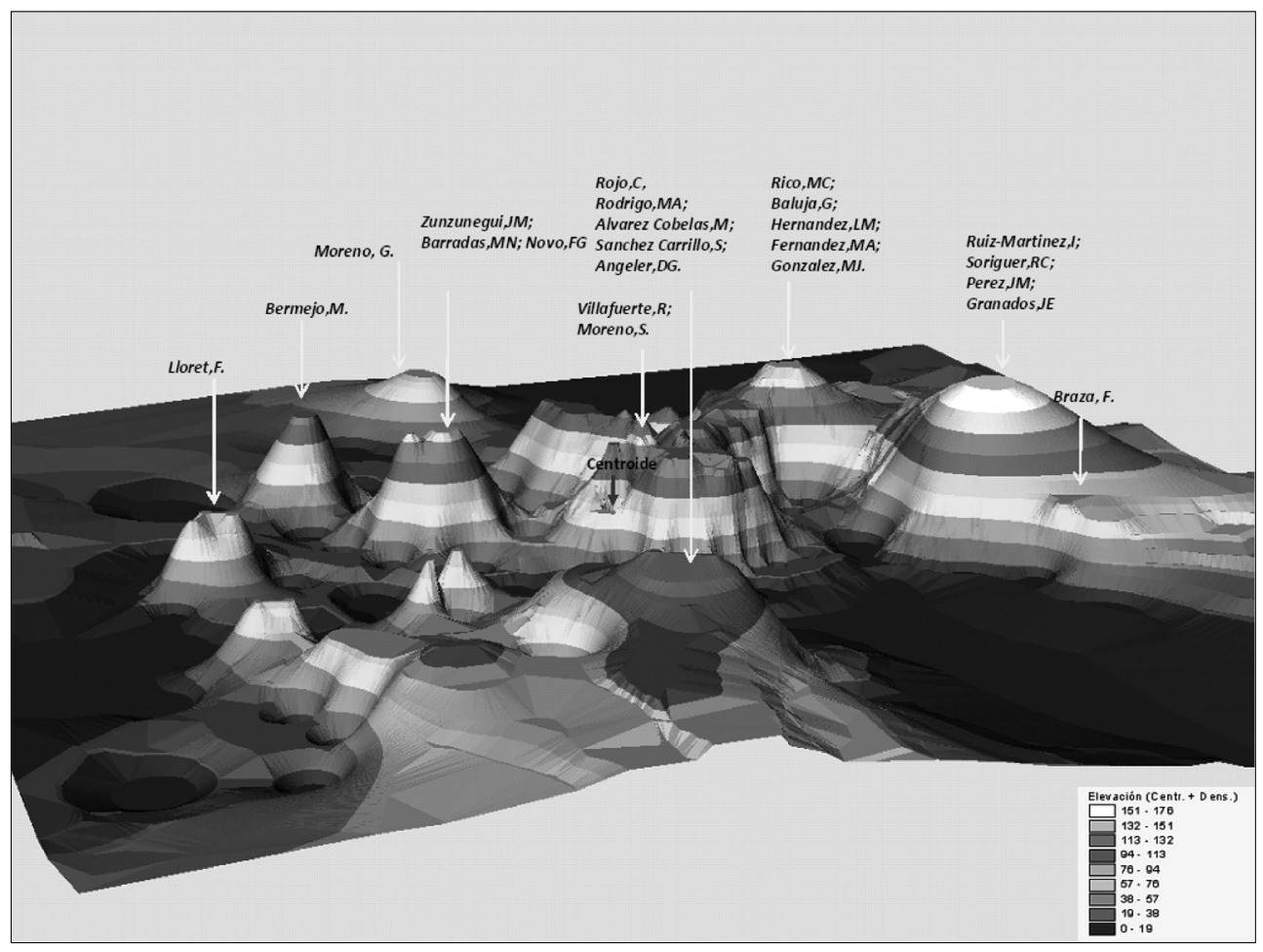

Fuente: Elaboración propia.

"Populations" es un término que aparece en subredes de los tres últimos periodos. Aparece en el período 1991-1995 formando parte de la subred «Populations", constituída por los términos "Populations" y "SW Spain"; continúa en el período 1996-2000 formando parte de la subred "Conservation", de ocho términos, y sigue en el período 2001-2005 formando parte de la subred de diez términos «Doñana National Park" (junto con los términos "Oryctolagus cuniculus" y "Conservation" que le acompañan de la subred "Conservation" del período anterior).

"Doñana National Park", es un término que aparece en subredes de los tres últimos periodos. Se inicia en el período 1991-1995 constituyendo una subred junto al término "Delibes, M.»; continúa en el período 1996-2000 formando parte de la subred de diez nodos «Doñana National Park" y permanece en el período 2001-2005 dando nombre a una nueva subred de diez nodos de igual nombre, «Doñana National Park»; el término "Oryctolagus cuniculus" le acompaña en el cambio 1996-2000 a 2001-2005. 
"Aznalcóllar mine toxic spill" es un término que forma parte de la subred «Heavy metals» del período 1996-2000 y de la subred «Doñaña National Park» del período 2001-2005. En los dos periodos le acompaña el término "Heavy metals".

\section{Análisis de actividad de las Subredes Estratégicas de Investigación}

Para visualizar la actividad de las diferentes subredes estratégicas a lo largo de los cinco quinquenios en los que se ha dividido el período de estudio (19812005), se ha consultado la fecha de publicación de cada uno de los documentos pertenecientes a cada una de las diferentes subredes estratégicas y se ha realizado una tabla en la que se han coloreado los periodos en los que se ha publicado (véase tabla III).

\section{TABLA III}

Periodos de actividad de las Subredes Estratégicas Españolas de Investigación sobre Áreas Protegidas de la Red WOS_PCAR_53210 (1981-2005)

\begin{tabular}{|c|c|c|c|c|c|c|c|c|}
\hline \multirow[b]{2}{*}{ Red } & \multirow{2}{*}{$\begin{array}{l}\text { Áreas de } \\
\text { investiga- } \\
\text { ción }\end{array}$} & \multirow{2}{*}{$\begin{array}{l}\text { Subredes } \\
\text { de } \\
\text { investiga- } \\
\text { ción }\end{array}$} & \multirow[b]{2}{*}{ PC, A y R } & \multicolumn{5}{|c|}{ Periodos de mayor actividad } \\
\hline & & & & $\begin{array}{l}1981 \\
1985\end{array}$ & $\begin{array}{l}1986 \\
1990\end{array}$ & $\begin{array}{l}1991 \\
1995\end{array}$ & $\begin{array}{l}1996 \\
2000\end{array}$ & $\begin{array}{l}2001 \\
2005\end{array}$ \\
\hline \multirow{6}{*}{$\begin{array}{c}\text { Web } \\
\text { of } \\
\text { Science }\end{array}$} & \multirow{6}{*}{$\begin{array}{c}\text { Parque } \\
\text { Nacional } \\
\text { de } \\
\text { Doñana }\end{array}$} & $\begin{array}{l}\text { Hemorr- } \\
\text { hagic } \\
\text { disease }\end{array}$ & $\begin{array}{l}\text { Oryctolagus-cuniculus; } \\
\text { Hemorrhagic-disease; Mo- } \\
\text { reno, S. y Villafuerte, R. }\end{array}$ & & & & & \\
\hline & & $\begin{array}{l}\text { Delibes, } \\
\text { M. }\end{array}$ & $\begin{array}{l}\text { Delibes,M.; Lynx-pardin- } \\
\text { us; Palomares, F.; Ferre- } \\
\text { ras, P.; Revilla, E.; Beltran, } \\
\text { J. F.; Fedriani, J. M. y Al- } \\
\text { dama, J. J. }\end{array}$ & & & & & \\
\hline & & $\begin{array}{l}\text { Zunzune- } \\
\text { gui, M. }\end{array}$ & $\begin{array}{l}\text { Shrubs; Novo, F. G.; Ba- } \\
\text { rradas, M. C. D. y Zunzu- } \\
\text { negui, M. }\end{array}$ & & & & & \\
\hline & & Baos, R. & $\begin{array}{l}\text { Hiraldo, F.; Arsenic; Baos, } \\
\text { R. y Montoro, R. }\end{array}$ & & & & & \\
\hline & & Zinc & $\begin{array}{l}\text { Soils, Cadmium, Pb, Zinc } \\
\text { y Copper }\end{array}$ & & & & & \\
\hline & & $\begin{array}{l}\text { Hernán- } \\
\text { dez, L. M. }\end{array}$ & $\begin{array}{l}\text { Hernández, L. M.; Gonzá- } \\
\text { lez, M. J.; Fernández, M. } \\
\text { A.; Bulletin-of-Environ- } \\
\text { mental-Contamination- } \\
\text { and-Toxicology; Rico, M. } \\
\text { C. y Baluja, G. }\end{array}$ & & & & & \\
\hline
\end{tabular}




\section{TABLA III (continuación)}

\begin{tabular}{|c|c|c|c|c|c|c|c|c|}
\hline \multirow[b]{2}{*}{ Red } & \multirow{2}{*}{$\begin{array}{l}\text { Áreas de } \\
\text { investiga- } \\
\text { ción }\end{array}$} & \multirow{2}{*}{$\begin{array}{l}\text { Subredes } \\
\text { de } \\
\text { investiga- } \\
\text { ción }\end{array}$} & \multirow[b]{2}{*}{ PC, A y R } & \multicolumn{5}{|c|}{ Periodos de mayor actividad } \\
\hline & & & & $\begin{array}{l}1981 \\
1985\end{array}$ & $\begin{array}{l}1986 \\
1990\end{array}$ & $\begin{array}{l}1991 \\
1995\end{array}$ & $\begin{array}{l}1996 \\
2000\end{array}$ & $\begin{array}{l}2001 \\
2005\end{array}$ \\
\hline \multirow{12}{*}{$\begin{array}{l}\text { Web } \\
\text { of } \\
\text { Science }\end{array}$} & \multirow{4}{*}{$\begin{array}{l}\text { Parque } \\
\text { Nacional } \\
\text { de } \\
\text { Doñana }\end{array}$} & $\begin{array}{l}\text { Del Valls, } \\
\text { T. A. }\end{array}$ & $\begin{array}{l}\text { Heavy-metals; Aznalco- } \\
\text { llar-mine-toxic-spill; Po- } \\
\text { llution; Guadiamar-River; } \\
\text { Guadalquivir-Estuary; Del } \\
\text { Valls, T. A.; Doñana-Na- } \\
\text { tional-Park y sW-Spain. }\end{array}$ & & & & & \\
\hline & & $\begin{array}{l}\text { Environ- } \\
\text { mental } \\
\text { Pollution- } \\
\text { R }\end{array}$ & $\begin{array}{l}\text { Contamination y Environ- } \\
\text { mental-Pollution-R }\end{array}$ & & & & & \\
\hline & & $\begin{array}{l}\text { Balbontín, } \\
\mathrm{J} .\end{array}$ & $\begin{array}{l}\text { Ferrer, M.; Aquila-adal- } \\
\text { berti; Age y Balbontin, J. }\end{array}$ & & & & & \\
\hline & & $\begin{array}{l}\text { Gómez } \\
\text { Ariza, J. L. }\end{array}$ & $\begin{array}{l}\text { Gómez-Ariza, J. L. y Se- } \\
\text { quential-extraction. }\end{array}$ & & & & & \\
\hline & \multirow[t]{2}{*}{$\begin{array}{c}\text { Álvarez } \\
\text { Cobelas, } \\
\text { M. }\end{array}$} & $\begin{array}{l}\text { Sánchez } \\
\text { Carrillo, S. }\end{array}$ & $\begin{array}{l}\text { Álvarez-Cobelas, M.; } \\
\text { Phytoplankton; Sánchez- } \\
\text { Carrillo, S.; Angeler, D. } \\
\text { G.; Rodrigo, M. A. y Rojo, } \\
\text { C. }\end{array}$ & & & & & \\
\hline & & $\begin{array}{l}\text { Wetlands- } \\
\text { R }\end{array}$ & Wetlands-R y Lakes. & & & & & \\
\hline & $\begin{array}{l}\text { Mediterra- } \\
\text { nean Sea }\end{array}$ & $\begin{array}{l}\text { Mediterra- } \\
\text { nean Sea }\end{array}$ & $\begin{array}{l}\text { Mediterranean-Sea y Ma- } \\
\text { rine-protected-areas. }\end{array}$ & & & & & \\
\hline & $\begin{array}{l}\text { Soriguer, } \\
\text { R. C. }\end{array}$ & $\begin{array}{l}\text { Soriguer, } \\
\text { R. C. }\end{array}$ & $\begin{array}{l}\text { Pérez,J.M.; Granados, J. } \\
\text { E.; Ruíz-Martínez, I.; Sie- } \\
\text { rra-Nevada-National-Park } \\
\text { y Soriguer, R. C. }\end{array}$ & & & & & \\
\hline & $\begin{array}{l}\text { Bermejo, } \\
\text { M. }\end{array}$ & $\begin{array}{l}\text { Bermejo, } \\
\text { M. }\end{array}$ & $\begin{array}{l}\text { Bermejo,M. y Gorilla-go- } \\
\text { rilla. }\end{array}$ & & & & & \\
\hline & Capa, M. & Capa, M. & $\begin{array}{l}\text { Capa, M.; Lopez, E; San } \\
\text { Martin,G.; Panama; Poly- } \\
\text { chaeta y Syllidae. }\end{array}$ & & & & & \\
\hline & Lloret, F. & Lloret, F. & $\begin{array}{l}\text { Fire; Yellowstone-Natio- } \\
\text { nal-Park y LLoret, F. }\end{array}$ & & & & & \\
\hline & Braza, F. & Braza, F. & $\begin{array}{l}\text { Braza, F. y Cervus ela- } \\
\text { phus. }\end{array}$ & & & & & \\
\hline
\end{tabular}




\section{TABLA III (continuación)}

\begin{tabular}{|c|c|c|c|c|c|c|c|c|}
\hline \multirow[b]{2}{*}{ Red } & \multirow{2}{*}{$\begin{array}{l}\text { Áreas de } \\
\text { investiga- } \\
\text { ción }\end{array}$} & \multirow{2}{*}{$\begin{array}{l}\text { Subredes } \\
\text { de } \\
\text { investiga- } \\
\text { ción }\end{array}$} & \multirow[b]{2}{*}{ PC, A y R } & \multicolumn{5}{|c|}{ Periodos de mayor actividad } \\
\hline & & & & $\begin{array}{l}1981 \\
1985\end{array}$ & $\begin{array}{l}1986 \\
1990\end{array}$ & $\begin{array}{l}1991 \\
1995\end{array}$ & $\begin{array}{l}1996 \\
2000\end{array}$ & $\begin{array}{l}2001 \\
2005\end{array}$ \\
\hline \multirow{8}{*}{$\begin{array}{c}\text { Web } \\
\text { of } \\
\text { Science }\end{array}$} & \multirow{3}{*}{ Sala, E. } & $\begin{array}{l}\text { Species } \\
\text { richness }\end{array}$ & $\begin{array}{l}\text { Diversity y Species rich- } \\
\text { ness. }\end{array}$ & & & & & \\
\hline & & $\begin{array}{c}\text { García Ru- } \\
\text { bies, A. }\end{array}$ & $\begin{array}{l}\text { Marine-reserves; Assem- } \\
\text { blages y García-Rubies, } \\
\text { A. }\end{array}$ & & & & & \\
\hline & & Sala, E. & $\begin{array}{l}\text { Sala, E.; Zabala, M.; Co- } \\
\text { ral-reefs; Marine-Biolo- } \\
\text { gy-R y Population-struc- } \\
\text { ture. }\end{array}$ & & & & & \\
\hline & $\begin{array}{l}\text { Moreno, } \\
\quad \text { G. }\end{array}$ & $\begin{array}{l}\text { Moreno, } \\
\text { G. }\end{array}$ & $\begin{array}{l}\text { Cryptogamie-Mycologie-R } \\
\text { y Moreno, G. }\end{array}$ & & & & & \\
\hline & \multicolumn{8}{|c|}{ Subredes motor de investigación (centrales y densas). } \\
\hline & \multicolumn{8}{|c|}{ Subredes generalistas (centrales y no densas). } \\
\hline & \multicolumn{8}{|c|}{ Subredes adyacentes (no centrales y densas). } \\
\hline & \multicolumn{8}{|c|}{ Subredes no consolidadas, nacientes o en desaparición (no centrales y no densas). } \\
\hline
\end{tabular}

\section{Revistas Estratégicas}

Las revistas que pertenecen a subredes estratégicas son las que aparecen en la tabla IV. En la tabla figuran tres columnas: rango de la revista según sus ocurrencias, número de ocurrencias y título de la revista.

\section{TABLA IV}

Revistas de importancia estratégica en la investigación española sobre Áreas Protegidas de la Red WOS PCAR 53210, 1981-2005

\begin{tabular}{c|c|l}
\hline Rango & Ocu & \multicolumn{1}{c}{ Revista } \\
\hline 3 & 13 & Science of the Total Environment \\
\hline 6 & 7 & Wetlands \\
\hline 14 & 6 & Environmental Pollution \\
\hline 16 & 6 & Bulletin of Environmental Contamination \\
\hline 17 & 5 & Marine Biology \\
\hline 23 & 5 & Cryptogamie Mycologie \\
\hline
\end{tabular}




\section{Investigadores Estratégicos}

Los Investigadores que forman parte de subredes estratégicas son los que se detallan en la tabla V. En ellas figuran el Centro, Departamento, Grupo y líneas de investigación del investigador (datos obtenidos de la web a la fecha de realización del presente trabajo).

\section{TABLA V}

Investigadores de importancia estratégica en la investigación española de visibilidad internacional sobre áreas protegidas de la Red WOS PCAR 53210 (1981-2005) (véase nota 5)

\begin{tabular}{|c|c|c|c|c|}
\hline Investigador & $\begin{array}{l}\text { Departamen- } \\
\text { to }\end{array}$ & Centro & Grupo & Líneas de investigación \\
\hline $\begin{array}{l}\text { María Cruz } \\
\text { Díaz } \\
\text { Antúnez- } \\
\text { Barradas }\end{array}$ & \multirow[t]{2}{*}{$\begin{array}{l}\text { Biología Ve- } \\
\text { getal y Eco- } \\
\text { logía }\end{array}$} & \multirow[t]{2}{*}{$\begin{array}{l}\text { Universidad } \\
\text { de Sevilla }\end{array}$} & $\begin{array}{l}\text { Producción de } \\
\text { Compuestos de } \\
\text { Interés Industrial } \\
\text { por Microalgas y } \\
\text { Plantas. }\end{array}$ & $\begin{array}{l}\text { Determinación de las condicio- } \\
\text { nes óptimas para el crecimiento } \\
\text { y acumulación de carotenoides } \\
\text { de interés industrial por microal- } \\
\text { gas. Búsqueda de mutantes de } \\
\text { microalgas superproductores de } \\
\text { carotenoides de interés. Estudio } \\
\text { del ciclo de vida de haematococ- } \\
\text { cus pluvialis y su relación con la } \\
\text { síntesis de astaxantina. Estudio } \\
\text { de la regulación de la síntesis de } \\
\text { luteína y astaxantina en Chlore- } \\
\text { lla. Papel del ciclo de las xanto- } \\
\text { filas. }\end{array}$ \\
\hline $\begin{array}{l}\text { María } \\
\text { Zunzunegui } \\
\text { González }\end{array}$ & & & $\begin{array}{l}\text { Ecologia de } \\
\text { Aguas Continen- } \\
\text { tales y Ecosiste- } \\
\text { mas Terrestres; } \\
\text { Limnologia; Ges- } \\
\text { tión de Recursos } \\
\text { Naturales }\end{array}$ & $\begin{array}{l}\text { Ecología de los sistemas litorales. } \\
\text { - Dinámica de nutrientes en eco- } \\
\text { sistemas acuáticos. - Estructura } \\
\text { de las comunidades acuáticas. - } \\
\text { Estrategias morfofisiológicas de } \\
\text { tipos funcionales. - morfología y } \\
\text { ecofisiología de especies dioicas. } \\
\text { Dinámica de arroyos tempora- } \\
\text { les. Restauración de ecosiste- } \\
\text { mas. Limnologia de lagunas y } \\
\text { embalses. }\end{array}$ \\
\hline $\begin{array}{l}\text { Sacramento } \\
\text { Moreno }\end{array}$ & $\begin{array}{l}\text { Conserva- } \\
\text { ción de la } \\
\text { Biodiversi- } \\
\text { dad }\end{array}$ & EBD-CSIC & Grupo Moreno & $\begin{array}{l}\text { Biología de la conservación y } \\
\text { cambio global e invasiones bio- } \\
\text { lógicas, biología evolutiva y eco- } \\
\text { logía molecular y genética evolu- } \\
\text { tiva }\end{array}$ \\
\hline
\end{tabular}


TABLA V (continuación)

\begin{tabular}{|c|c|c|c|c|}
\hline Investigador & $\begin{array}{l}\text { Departamen- } \\
\text { to }\end{array}$ & Centro & Grupo & Líneas de investigación \\
\hline $\begin{array}{l}\text { Rafael } \\
\text { Villafuerte } \\
\text { Fernández }\end{array}$ & Ecología & $\begin{array}{l}\text { IREC (CSIC- } \\
\text { U C L M - J C - } \\
\text { CM) }\end{array}$ & $\begin{array}{l}\text { Gestión de la } \\
\text { fauna: caza y } \\
\text { conservación. }\end{array}$ & $\begin{array}{l}\text { Factores que determinan la dis- } \\
\text { tribución y las tendencias de las } \\
\text { especies de fauna, principalmen- } \\
\text { te de caza menor. Selección } \\
\text { sexual y caracteres sexuales se- } \\
\text { cundarios en la perdiz roja. Eco- } \\
\text { logía, dinámica de población y } \\
\text { gestión de poblaciones de cone- } \\
\text { jos silvestres y perdices rojas. } \\
\text { Mejora de técnicas de gestión ta- } \\
\text { les como las repoblaciones de } \\
\text { conejos con finalidades tanto de } \\
\text { caza como conservación. Interac- } \\
\text { ción entre agricultura, gestión de } \\
\text { la caza y conservación de la bio- } \\
\text { diversidad: estudio y resolución } \\
\text { de conflictos tales como el gene- } \\
\text { rado por interacciones predador- } \\
\text { presa }\end{array}$ \\
\hline $\begin{array}{l}\text { Gonzalo } \\
\text { Baluja }\end{array}$ & \multirow{5}{*}{$\begin{array}{l}\text { Análisis Ins- } \\
\text { trumental y } \\
\text { Q u ím i c a } \\
\text { Ambiental }\end{array}$} & \multirow{5}{*}{ IQOG-CSIC } & \multirow{5}{*}{$\begin{array}{l}\text { Química Am- } \\
\text { biental }\end{array}$} & \multirow{5}{*}{$\begin{array}{l}\text { Desarrollo de metodologías ana- } \\
\text { líticas innovadoras en química } \\
\text { ambiental. Estudio de comporta- } \\
\text { miento de contaminantes tóxicos } \\
\text { y persistentes en el medio am- } \\
\text { biente, incluído el hombre. }\end{array}$} \\
\hline $\begin{array}{l}\text { Mario } \\
\text { Antonio } \\
\text { Fernández } \\
\text { Martín }\end{array}$ & & & & \\
\hline $\begin{array}{l}\text { María José } \\
\text { González } \\
\text { Carlos }\end{array}$ & & & & \\
\hline $\begin{array}{l}\text { Luis M. } \\
\text { Hernández } \\
(\dagger)\end{array}$ & & & & \\
\hline $\begin{array}{l}\text { María del } \\
\text { Carmen } \\
\text { Rico }\end{array}$ & & & & \\
\hline $\begin{array}{l}\text { Raquel Baos } \\
\text { Sendarrubias }\end{array}$ & \multirow[b]{2}{*}{$\begin{array}{l}\text { Biología de } \\
\text { la Conserva- } \\
\text { ción }\end{array}$} & \multirow[b]{2}{*}{ EBD-CSIC } & \multirow[b]{2}{*}{$\begin{array}{l}\text { Biología de la } \\
\text { Conservación }\end{array}$} & \multirow{2}{*}{$\begin{array}{l}\text { Ecología evolutiva, ecología del } \\
\text { comportamiento, ecología espa- } \\
\text { cial de poblaciones, interaccio- } \\
\text { nes, demografía y dinámica de } \\
\text { poblaciones, patrones de extin- } \\
\text { ción, genética de la conserva- } \\
\text { ción. }\end{array}$} \\
\hline $\begin{array}{l}\text { Fernando } \\
\text { Hiraldo } \\
\text { Cano }\end{array}$ & & & & \\
\hline
\end{tabular}


TABLA V (continuación)

\begin{tabular}{|c|c|c|c|c|}
\hline Investigador & $\begin{array}{c}\text { Departamen- } \\
\text { to }\end{array}$ & Centro & Grupo & Líneas de investigación \\
\hline $\begin{array}{l}\text { Rosa } \\
\text { Montoro } \\
\text { Martínez }\end{array}$ & $\begin{array}{l}\text { Conserva- } \\
\text { ción y Cali- } \\
\text { dad de los } \\
\text { Alimentos }\end{array}$ & IATA-CSIC & $\begin{array}{l}\text { Contaminación } \\
\text { metálica }\end{array}$ & $\begin{array}{l}\text { Desarrollo de metodologías ana- } \\
\text { líticas convencionales y rápidas } \\
\text { para el análisis de elementos tra- } \\
\text { za tóxicos y sus especies quími- } \\
\text { cas. Transformaciones cualitativas } \\
\text { y cuantitativas de contaminantes } \\
\text { metálicos durante la elaboración } \\
\text { y el almacenamiento. Ingestas de } \\
\text { elementos traza tóxicos mediante } \\
\text { estudios de Dieta Total. Biodispo- } \\
\text { nibilidad de arsénico, mercurio y } \\
\text { sus especies mediante métodos } \\
\text { de digestión in vitro y cultivos } \\
\text { celulares. }\end{array}$ \\
\hline $\begin{array}{l}\text { Tomás } \\
\text { Ángel del } \\
\text { Valls Casillas }\end{array}$ & $\begin{array}{l}\text { Química Fí- } \\
\text { sica }\end{array}$ & $\begin{array}{l}\text { Universidad } \\
\text { de Cádiz }\end{array}$ & $\begin{array}{l}\text { Oceanografía y } \\
\text { contaminación } \\
\text { del litoral }\end{array}$ & $\begin{array}{l}\text { Contaminación Marina. Procesos } \\
\text { de Transferencia a través de las } \\
\text { Interfases del Mar. }\end{array}$ \\
\hline $\begin{array}{l}\text { José Luis } \\
\text { Gómez-Ari- } \\
\text { za }\end{array}$ & $\begin{array}{l}\text { Química y } \\
\text { Ciencia de } \\
\text { los Materia- } \\
\text { les }\end{array}$ & $\begin{array}{l}\text { Universidad } \\
\text { de Huelva }\end{array}$ & & \\
\hline $\begin{array}{l}\text { J. J. Aldama } \\
(\dagger)\end{array}$ & $\begin{array}{l}\text { Centro de El } \\
\text { Acebuche }\end{array}$ & $\begin{array}{lr}\text { Parque } & \mathrm{Na}- \\
\text { cional } & \mathrm{de} \\
\text { Doñana } & \end{array}$ & & \\
\hline $\begin{array}{l}\text { Juan } \\
\text { Francisco } \\
\text { Beltrán Gala }\end{array}$ & $\begin{array}{l}\text { Fisiología y } \\
\text { Zoología }\end{array}$ & $\begin{array}{l}\text { Universidad } \\
\text { de Sevilla }\end{array}$ & $\begin{array}{l}\text { Estudio de Ver- } \\
\text { tebrados }\end{array}$ & \\
\hline $\begin{array}{l}\text { Miguel } \\
\text { Delibes de } \\
\text { Castro }\end{array}$ & \multirow{3}{*}{$\begin{array}{l}\text { Biología de } \\
\text { la Conserva- } \\
\text { ción }\end{array}$} & \multirow{4}{*}{ EBD-CSIC } & \multirow{3}{*}{$\begin{array}{l}\text { Biología de la } \\
\text { Conservación }\end{array}$} & \multirow{3}{*}{$\begin{array}{l}\text { Ecología evolutiva, ecología del } \\
\text { comportamiento, ecología espa- } \\
\text { cial de poblaciones, interaccio- } \\
\text { nes, demografía y dinámica de } \\
\text { poblaciones, patrones de extin- } \\
\text { ción, genética de la conservación. }\end{array}$} \\
\hline $\begin{array}{l}\text { Francisco } \\
\text { Palomares } \\
\text { Fernández }\end{array}$ & & & & \\
\hline $\begin{array}{l}\text { Eloy Revilla } \\
\text { Sánchez }\end{array}$ & & & & \\
\hline $\begin{array}{l}\text { Jose María } \\
\text { Fedriani } \\
\text { Laffitte }\end{array}$ & & & & Interacciones entre especies. \\
\hline
\end{tabular}


TABLA V (continuación)

\begin{tabular}{|c|c|c|c|c|}
\hline Investigador & $\begin{array}{l}\text { Departamen- } \\
\text { to }\end{array}$ & Centro & Grupo & Líneas de investigación \\
\hline $\begin{array}{l}\text { Pablo } \\
\text { Ferreras de } \\
\text { Andrés }\end{array}$ & Ecología & $\begin{array}{l}\text { IREC (CSIC- } \\
\text { U C L M - J C - } \\
\text { CM), }\end{array}$ & $\begin{array}{l}\text { Gestión de la } \\
\text { fauna: caza y } \\
\text { conservación }\end{array}$ & $\begin{array}{l}\text { Factores que determinan la distri- } \\
\text { bución y las tendencias de las } \\
\text { especies de fauna, principalmen- } \\
\text { te de caza menor. Selección } \\
\text { sexual y caracteres sexuales se- } \\
\text { cundarios en la perdiz roja, gía, } \\
\text { dinámica de población y gestión } \\
\text { de poblaciones de conejos silves- } \\
\text { tres y perdices rojas. Mejora de } \\
\text { técnicas de gestión tales como las } \\
\text { repoblaciones de conejos con fi- } \\
\text { nalidades tanto de caza como } \\
\text { conservación. }\end{array}$ \\
\hline $\begin{array}{l}\text { José Enrique } \\
\text { Granados } \\
\text { Torres }\end{array}$ & \multirow{3}{*}{$\begin{array}{l}\text { Biología Ani- } \\
\text { mal, Biolo- } \\
\text { gía Vegetal y } \\
\text { Ecología }\end{array}$} & Egmasa & \multirow{4}{*}{$\begin{array}{l}\text { Biología de las } \\
\text { especies cinegé- } \\
\text { ticas y plagas }\end{array}$} & \multirow{4}{*}{$\begin{array}{l}\text { Estudio, manejo y recuperación } \\
\text { de las poblaciones de interés ci- } \\
\text { negético en Andalucía. Estudios } \\
\text { de agentes patógenos en ungula- } \\
\text { dos y lagomorfos silvestres. Ge- } \\
\text { nética de poblaciones de especies } \\
\text { cinegéticas. Genética de pobla- } \\
\text { ciones de artrópodos parásitos. } \\
\text { Biología y ecología de especies } \\
\text { cinegéticas y plaga. }\end{array}$} \\
\hline $\begin{array}{l}\text { Jesús María } \\
\text { Pérez } \\
\text { Jiménez }\end{array}$ & & $\begin{array}{l}\text { Universidad } \\
\text { de Jaén }\end{array}$ & & \\
\hline $\begin{array}{l}\text { Isidoro Ruíz } \\
\text { Martínez (†) }\end{array}$ & & & & \\
\hline $\begin{array}{l}\text { Ramón } \\
\text { Casimiro- } \\
\text { Soriguer } \\
\text { Escofet }\end{array}$ & & EBD-CSIC & & \\
\hline $\begin{array}{l}\text { Miguel } \\
\text { Álvarez } \\
\text { Cobelas }\end{array}$ & $\begin{array}{l}\text { Ecología de } \\
\text { sistemas }\end{array}$ & CCM-CSIC & $\begin{array}{l}\text { Biogeoquímica } \\
\text { de Ecosistemas }\end{array}$ & $\begin{array}{l}\text { Evaluación de los efectos induci- } \\
\text { dos por el hombre en el medio } \\
\text { ambiente en los ciclos biogeoquí- } \\
\text { micos y estructura y función de } \\
\text { los ecosistemas acuáticos y te- } \\
\text { rrestres. }\end{array}$ \\
\hline $\begin{array}{l}\text { David } \\
\text { Angeler }\end{array}$ & $\begin{array}{l}\text { Ecosistemas } \\
\text { y recursos } \\
\text { naturales }\end{array}$ & ICAM-UCLM & Ecología acuática & \\
\hline
\end{tabular}


TABLA V (continuación)

\begin{tabular}{|c|c|c|c|c|}
\hline Investigador & $\begin{array}{c}\text { Departamen- } \\
\text { to }\end{array}$ & Centro & Grupo & Líneas de investigación \\
\hline $\begin{array}{l}\text { Maria } \\
\text { Antonia } \\
\text { Rodrigo } \\
\text { Alacreu }\end{array}$ & & & & $\begin{array}{l}\text { Biodiversidad del plancton dulce- } \\
\text { acuícula. Variación espacio-tem- } \\
\text { poral de las comunidades planc- } \\
\text { tónicas: Series temporales largas }\end{array}$ \\
\hline $\begin{array}{l}\text { Carmen } \\
\text { Rojo } \\
\text { García-Mo- } \\
\text { rato }\end{array}$ & $\begin{array}{l}\text { Instituto Ca- } \\
\text { vanilles de } \\
\text { Biodiversi- } \\
\text { dad y Biolo- } \\
\text { gía Evolutiva. } \\
\text { Departamen- } \\
\text { to de Micro- } \\
\text { biología y } \\
\text { Ecología }\end{array}$ & $\begin{array}{l}\text { Universitat } \\
\text { de Valencia }\end{array}$ & $\begin{array}{l}\text { Grupo Ecología } \\
\text { Integrativa }\end{array}$ & $\begin{array}{l}\text { pacial de las metacomunidades. } \\
\text { Variación de las comunidades } \\
\text { planctónicas como efecto de los } \\
\text { cambios globales. Ensamblado de } \\
\text { las comunidades y efectos del or- } \\
\text { den de invasión sobre la estabili- } \\
\text { dad de la comunidad. Desensam- } \\
\text { blado de las comunidades o } \\
\text { efecto de la pérdida de especies. } \\
\text { Mecanismos de interacción entre } \\
\text { especies en el marco de la diná- } \\
\text { mica de auto-organización del } \\
\text { sistema. Competencia, depreda- } \\
\text { ción, omnivoría y alelopatía en- } \\
\text { tres especies co-ocurrentes en los } \\
\text { sistemas acuáticos. Estudio de re- } \\
\text { des tróficas (desde la dinámica de } \\
\text { su topología hasta el modelo de } \\
\text { función). }\end{array}$ \\
\hline $\begin{array}{l}\text { Salvador } \\
\text { Sánchez } \\
\text { Carrillo }\end{array}$ & $\begin{array}{l}\text { Ecología de } \\
\text { sistemas }\end{array}$ & CCM-CSIC & $\begin{array}{l}\text { Biogeoquímica } \\
\text { de Ecosistemas }\end{array}$ & $\begin{array}{l}\text { Evaluación de los efectos induci- } \\
\text { dos por el hombre en el medio } \\
\text { ambiente en los ciclos biogeo- } \\
\text { químicos y estructura y función } \\
\text { de los ecosistemas acuáticos y te- } \\
\text { rrestres. }\end{array}$ \\
\hline $\begin{array}{l}\text { Magdalena } \\
\text { Bermejo } \\
\text { Espinet }\end{array}$ & $\begin{array}{l}\text { Biología Ani- } \\
\text { mal }\end{array}$ & $\begin{array}{l}\text { Universitat } \\
\text { de Barcelo- } \\
\text { na }\end{array}$ & & $\begin{array}{l}\text { Conservación y desarrollo soste- } \\
\text { nible en ecosistemas tropicales } \\
\text { africanos. Estudio del comporta- } \\
\text { miento social del gorila de llanu- } \\
\text { ra (Gorilla g. gorilla) en particular, } \\
\text { y de los grandes simios en gene- } \\
\text { ral, que ha permitido avanzar en } \\
\text { una línea de desarrollo sostenible } \\
\text { basada en el ecoturismo. Se está } \\
\text { siguiendo la evolución de las po- } \\
\text { blaciones que han sido diezma- } \\
\text { das por el ébola. }\end{array}$ \\
\hline
\end{tabular}


TABLA V (continuación)

\begin{tabular}{|c|c|c|c|c|}
\hline Investigador & $\begin{array}{c}\text { Departamen- } \\
\text { to }\end{array}$ & Centro & Grupo & Líneas de investigación \\
\hline María Capa & $\begin{array}{l}\text { R e s e a r ch } \\
\text { and Collec- } \\
\text { tions }\end{array}$ & $\begin{array}{l}\text { Australian } \\
\text { M u s e u m, } \\
\text { Sydney, Aus- } \\
\text { tralia }\end{array}$ & $\begin{array}{l}\text { Marine Inverte- } \\
\text { brates }\end{array}$ & $\begin{array}{l}\text { Sistemática y filogenia de Sabelli- } \\
\text { da (Polychaeta). }\end{array}$ \\
\hline $\begin{array}{l}\text { Eduardo } \\
\text { López } \\
\text { García }\end{array}$ & \multirow{2}{*}{ Biología } & \multirow{2}{*}{$\begin{array}{l}\text { Universidad } \\
\text { Autónoma } \\
\text { de Madrid }\end{array}$} & & \\
\hline $\begin{array}{l}\text { Guillermo } \\
\text { San Martín } \\
\text { Peral }\end{array}$ & & & Biología Marina & \\
\hline $\begin{array}{l}\text { Javier } \\
\text { Balbontín } \\
\text { Arenas }\end{array}$ & $\begin{array}{l}\text { Fisiología y } \\
\text { Zoología }\end{array}$ & $\begin{array}{l}\text { Universidad } \\
\text { de Sevilla }\end{array}$ & $\begin{array}{l}\text { Conservación de } \\
\text { la Biodiversidad }\end{array}$ & \\
\hline $\begin{array}{l}\text { Miguel } \\
\text { Ángel Ferrer } \\
\text { Baena }\end{array}$ & $\begin{array}{l}\text { Conserva- } \\
\text { ción de la } \\
\text { Biodiversi- } \\
\text { dad }\end{array}$ & EBD-CSIC & $\begin{array}{l}\text { Grupo Miguel } \\
\text { Ferrer }\end{array}$ & $\begin{array}{l}\text { Biología de la conservación y } \\
\text { Cambio Global e Invasiones Bio- } \\
\text { lógicas Biología Evolutiva y Eco- } \\
\text { logía Molecular y Genética Evo- } \\
\text { lutiva. }\end{array}$ \\
\hline $\begin{array}{l}\text { Enric Sala } \\
\text { Gamito }\end{array}$ & $\begin{array}{l}\text { Ecología Ma- } \\
\text { rina }\end{array}$ & CEAB-CSIC & $\begin{array}{l}\text { Investigación de } \\
\text { Biodiversidad y } \\
\text { Ecología del } \\
\text { Bentos Marino }\end{array}$ & $\begin{array}{l}\text { Conocer la organización y funcio- } \\
\text { namiento de los ecosistemas ben- } \\
\text { tónicos marinos y los mecanismos } \\
\text { que los regulan. La fusión de mo- } \\
\text { dernas técnicas moleculares con } \\
\text { estudios biológicos y ecológicos } \\
\text { tradicionales, permiten tener una } \\
\text { aproximación amplia, que va des- } \\
\text { de el nivel molecular al de orga- } \\
\text { nismos, poblaciones, comunida- } \\
\text { des y ecosistemas. }\end{array}$ \\
\hline $\begin{array}{l}\text { Mikel } \\
\text { Zabala } \\
\text { Limousin }\end{array}$ & Ecología & $\begin{array}{l}\text { Universidad } \\
\text { de Barcelo- } \\
\text { na }\end{array}$ & Ecología Marina & \\
\hline $\begin{array}{l}\text { Francisco } \\
\text { Lloret Maya }\end{array}$ & & CREAF-UAB & Incendios & $\begin{array}{l}\text { Prevención del riesgo de incendio } \\
\text { forestal. Estudio y modelización } \\
\text { del régimen de incendios. Fuegos } \\
\text { de copas y modelos de combus- } \\
\text { tibles. Efecto del fuego sobre las } \\
\text { plantas. Recuperación de la fauna } \\
\text { después de incendios. Gestión de } \\
\text { zonas quemadas. }\end{array}$ \\
\hline
\end{tabular}




\begin{tabular}{|c|c|c|c|c|}
\hline Investigador & $\begin{array}{l}\text { Departamen- } \\
\text { to }\end{array}$ & Centro & Grupo & Líneas de investigación \\
\hline $\begin{array}{l}\text { Antonio } \\
\text { García } \\
\text { Rubies }\end{array}$ & $\begin{array}{l}\text { Ecología Ma- } \\
\text { rina }\end{array}$ & CEAB-CSIC & $\begin{array}{l}\text { Investigación de } \\
\text { Biodiversidad y } \\
\text { Ecología del } \\
\text { Bentos Marino }\end{array}$ & $\begin{array}{l}\text { Conocer la organización y funcio- } \\
\text { namiento de los ecosistemas ben- } \\
\text { tónicos marinos y los mecanismos } \\
\text { que los regulan. La fusión de mo- } \\
\text { dernas técnicas moleculares con } \\
\text { estudios biológicos y ecológicos } \\
\text { tradicionales, permiten tener una } \\
\text { aproximación amplia, que va des- } \\
\text { de el nivel molecular al de orga- } \\
\text { nismos, poblaciones, comunida- } \\
\text { des y ecosistemas. }\end{array}$ \\
\hline $\begin{array}{l}\text { Gabriel } \\
\text { Moreno } \\
\text { Horcajada }\end{array}$ & $\begin{array}{l}\text { Biología Ve- } \\
\text { getal }\end{array}$ & $\begin{array}{l}\text { Universidad } \\
\text { de Alcalá }\end{array}$ & & Micología \\
\hline $\begin{array}{l}\text { Francisco } \\
\text { Braza Lloret }\end{array}$ & $\begin{array}{l}\text { Etología y } \\
\text { Conserva- } \\
\text { ción de Re- } \\
\text { cursos Natu- } \\
\text { rales. }\end{array}$ & EBD-CSIC & Etología & $\begin{array}{l}\text { Estudios de campo experimentales } \\
\text { en la ecología comportamental de } \\
\text { aves y, en menor grado, mamífe- } \\
\text { ros (principalmente ungulados). } \\
\text { Ecología evolutiva y de comporta- } \\
\text { miento, evolución de señales de } \\
\text { comunicación, coevolución entre } \\
\text { parásitos y sus hospedadores, re- } \\
\text { des sociales y desarrollo social hu- } \\
\text { mano. Conservación de especies } \\
\text { amenazadas (como el Ibis eremi- } \\
\text { ta), control de especies invasoras } \\
\text { (Hormiga argentina) ... }\end{array}$ \\
\hline
\end{tabular}

Nota:

EBD-CSIC: Estación Biológica de Doñana (Consejo Superior de Investigaciones Científicas).

IREC (CSIC-UCLM-JCCM): Instituto de Investigación en Recursos Cinegéticos (Consejo Superior de Investigaciones Científicas, Universidad de Castilla La Mancha y Junta de Comunidades de Castilla La Mancha).

IQOG-CSIC: Instituto de Química Orgánica (Consejo Superior de Investigaciones Científicas).

IATA-CSIC: Instituto de Agroquímica y de Tecnología de los Alimentos (Consejo Superior de Investigaciones Científicas).

EGMASA: Empresa de Gestión Medioambiental (Consejería de Medio Ambiente, Junta de Andalucía).

CCM-CSIC: Centro de Ciencias Medioambientales (Consejo Superior de Investigaciones Científicas).

ICAM-UCLM: Instituto de Ciencias Ambientales (Universidad de Castilla la Mancha).

CEAB-CSIC: Centro de Estudios Avanzados de Blanes (Consejo Superior de Investigaciones Científicas).

CREAF-UAB: Centro de Investigaciones Ecológicas y Aplicaciones Forestales (Universidad Autónoma de Barcelona). 


\section{Conclusiones}

Las subredes tecnocientíficas están formadas por términos que han establecido entre sí durante el período de estudio relaciones cognitivas (palabra clave/ palabra clave, palabra clave/investigador o palabra clave/revista), relaciones de colaboración (investigador/investigador) o de publicación (investigador/revista) que pueden ser muy intensas en un corto período o menos intensas pero permanentes a lo largo del tiempo. La acción conjunta de todas esas diferentes relaciones de asociación entre los términos va a determinar la situación de cada uno en la red, es decir, su centralidad. Los términos mejor relacionados van a aparecer próximos entre sí constituyendo subredes; éstas, a su vez, también se van a situar en la red según su similitud, constituyendo áreas de investigación. La densidad de cada grupo o subred va a venir dada por la fortaleza de los enlaces entre los términos que la forman. Centralidad y densidad son los parámetros que van a determinar la posición estratégica del grupo o subred en el diagrama estratégico de la red. En consecuencia, en el análisis estratégico de redes tecnocientíficas la pertenencia de un término a una subred o grupo estratégico es fruto del número y tipo de relaciones cognitivas o enlaces que establece con el resto de términos a lo largo del tiempo y de la fortaleza de esos enlaces; se comprueba, por ejemplo, como de los cincuenta y tres investigadores de la red tecnocientífica (investigadores de cinco o más ocurrencias y que forman pares de tres o más coocurrencias con otros nodos) sólo cuarenta y tres pueden ser considerados como investigadores estratégicos.

El análisis estratégico y dinámico de la Red Tecnocientífica Española de Investigación sobre Áreas Protegidas permite dirigir y graduar las acciones en investigación, innovación y desarrollo hacia las áreas y subredes según su posición estratégica en la red. Entre las acciones futuras de gestión podría interesar apoyar la conversión de subredes periféricas y densas en subredes motor de investigación, incentivando las relaciones externas de las primeras, fortalecer las subredes generalistas, fomentando las relaciones internas, y apoyar las subredes nacientes o no consolidadas.

Los informes, listados, grafos y mapas fruto del análisis estratégico y dinámico de la Red WOS PCAR 53210 (1981-2005) sobre Áreas Protegidas pueden ser empleados en la evaluación estratégica científica y tecnológica de los actores de la investigación (palabras clave, investigadores o revistas), ya que caracterizan y sitúan a cada término según su importancia absoluta o su importancia estratégica en la red.

Los Mapas de Conocimiento Estratégico de la Red Tecnocientífica, Mapas CERT, facilitan el proceso de toma de decisiones ya que proporcionan imágenes estratégicas, "metáforas visuales de paisaje" del dominio científico y tecnológico analizado, que permiten asimilar gran cantidad de información relevante e importante de una manera rápida y comprensible. En ellos los términos se posicionan referenciados al Centroide de la Red según su centralidad (medida de su similitud con el objeto de estudio, en el caso que se presenta la "Investigación 
española sobre áreas protegidas recogida por la Web of Science durante 19812005") y en altura según su importancia absoluta en la red. La información visual se complementa con una simbología que traslada el Diagrama Estratégico de la Red al mapa cartográfico, de modo que en él los diferentes términos aparecen caracterizados según su importancia estratégica.

Los resultados obtenidos en el presente trabajo nos permiten considerar que la evaluación de redes tecnocientíficas mediante su análisis estratégico y dinámico y la visualización de sus grafos y Mapas CERT puede ser de gran utilidad en política científica y en evaluación de la Ciencia y la Tecnología en el campo de la administración y gestión de los espacios naturales protegidos en España.

\section{Bibliografía}

Aiello, A., y Silveira, R. I. (2004): Trazado de grafos mediante métodos dirigidos por fuerzas: revisión del estado del arte y presentación de algoritmos para grafos donde los vértices son regiones geográficas. http://www-ma2.upc.edu/rsilveira/pubs/MScThesis. pdf [consultado el 3 de abril de 2010].

Bailón-Moreno, R. (2003): Ingeniería del conocimiento y vigilancia tecnológica aplicada a la investigación en el campo de los tensioactivos. Desarrollo de un modelo ciencimétrico unificado. Granada: Tesis doctoral. Universidad de Granada.

Bailón-Moreno, R.; Jurado-Alameda, E., y Ruíz-Baños, R. (2006): The scientific network of surfactants: structutal analysis. Journal of the American Society for Information Science and Technology, 57 (7). 847-850.

Batagelj, V., y Mrvar, A. (s.f.) Networks/Pajek: Program for Large Network Analysis. http:// vlado.fmf.uni-lj.si/pub/networks/pajek/ [consultado el 4 de abril de 2010].

Callon, M. (1989): La science et ses réseaux: gènese et circulation des faits scientifiques. París: Découverte.

Callon, M.; Courtial. J., y Turner, W. (1991): La méthode Leximappe: un outil pour l'analyse stratégique du développement scientifique et technique. En B. Vinck, Gestion de la recherche: nouveaux problèmes, nouveaux outils, (207-277), Editions Bruxelles.

Callon, M.; Law, J., y Rip, A. (1986): Mapping the dynamics of science and technology: Sociology of science in the real world, Londres: McMillan Press LTD.

Courtial, J. P. (1999): Analyse dynamique des representations sociales des chercheurs: le cas de l'autisme. Papers on Social Representations, (8), 3.1-3.22.

Courtial, J. P., y Michelet, B. (1990): A mathematical model of development in research field. Scientometrics, 19 (1-2), 127-141.

Echevarría, J., y González, M. I. (2009): La Teoría del Actor-Red y la tesis de la Tecnociencia. Arbor Ciencia, Pensamiento y Cultura, (738), 705-720.

García-Ríos, M. C. (2009): El paradigma de la fisioterapia a través de un estudio ciencimétrico, Granada: Tesis doctoral, Universidad de Granada.

Jurado-Alameda, E.; Bailón-Moreno, R., y Ruíz-Baños, R. (2002a): Evaluación a través del análisis de palabras asociadas (I). Aplicación a la evaluación de la investigación científica y técnica. Ingeniería Química, (388), 141-149. 
Jurado-Alameda, E.; Bailón-Moreno, R., y Ruíz-Baños, R. (2002b): Evaluación a través del análisis de las palabras asociadas (II). Evaluación de la investigación en el campo de los tensioactivos. Ingeniería Química, 177-184.

Kamada, T., y Kawai, S. (1989): An algorithm for drawing general undirected graphs. Information Processing Letters, (31), 7-15.

Larreina, S.; Hernando, S., y Grisaleña, D. (enero-febrero de 2006): La evolución de la inteligencia competitiva: un estudio de las herramientas cienciométricas. Puzzle: Revista Hispana de Inteligencia Competitiva. http://redalyc.uaemex.mx/redalyc/ pdf/548/54852001.pdf [consultado el 3 de abril de 2010].

Latour, B. (1983): Give me a Laboratory and I Will Raise the World. En K. Knorr-Cetina, y M. Mulkay, Science observed: Perspectives on the Social Study of Science. Londres: Sage.

Latour, B. (2005): Reassembling the Social. An introduction to Actor-Metwork Theory. Oxford: Oxford University Press.

Law, J., y Whittaker, J. (1992): Mapping acidification research: a test of the co-word method. Scientometrics, 23 (3), 417-461.

Law, J.; Bauin, S.; Courtial, J. P., y Whittaker, J. (1988): Policy and the mapping of scientific change: a co-word analysis of research into enviromental acidification. Scientometrics, 14 (3-4), 251-264.

Michelet, B. (1988): L'analyse des associations. PhD Thesis. París: Université de París, 7.

Old, J. (2001): Utilizing Spatial Information Systems for Non-Spatial-Data Analysis. Scientometrics, vol. 51 (3), 563-571.

Pino-Díaz, J.; Jiménez-Contreras, E.; Ruíz-Baños, R., y Bailón-Moreno, R. (2009): Visualitation des acteurs-reseaux a travers les cartes SIG. Seminario VSST'09 (Vigilancia estratégica científica y tecnológica) (1-19). Nancy (Francia).

Polanco, X. (1997): Infometría e Ingeniería del Conocimiento: Exploración de Datos y Análisis de la Información en vista del Descubrimiento de Conocimientos. En Jaramillo, H., y Albornoz, M. (editores) El universo de la medición: La perspectiva de la Ciencia y la Tecnología. COLCIENCIAS, CYTED, RICYT. Tercer Mundo Editores. Bogotá, Colombia.

Polanco, X. (2008): Transformer l'information en connaissance avec STANALYST. Cadre conceptuel et Modèle. Encontros Bibli: Revista Electrónica Biblioteconomia y Ciencia de la Informaçao, n. ${ }^{\circ}$ esp., $1 .^{\circ}$ sem., 76-91.

Ruíz-Baños, R. (1997): Ciencimetría de redes. Análisis de la Investigación Internacional sobre Arqueología mediante el método de las palabras asociadas (1980-1993). Tesis Doctoral. Granada: Universidad de Granada.

Ruíz-Baños, R. (1996): Leximappe una eficaz herramienta informática para descibir la estructura de las redes del conocimiento científico. Sistemas de Información. Balance de 12 años de jornadas y perspectivas de futuro, 791-796, Cáceres: Fesabid.

Ruíz-Baños, R. (1999): Las traducciones dinámicas de las series temáticas. Propuesta de una clasificación. La Representación y la organización del conocimiento en sus distintas perspectivas: su influencia en la recuperación de la información: actas del IV Congreso ISKO-España, 211-216. Granada, España. 


\section{Notas}

1. El desarrollo en los años ochenta de la Sociología de las Ciencias y Técnicas, Sociología de la Traducción o Sociología de las Asociaciones por Michel Callon y Bruno Latour (Centre de Sociologie de l'Innovation, Paris) a partir de recursos conceptuales, entre otros, de Michel Serres (Filosofía de las Ciencias) y de David Bloor (Sociología del Conocimiento), tiene su exponente en la Teoría Actor-Red (ANT en inglés), según la cual, en la construcción social de un hecho científico intervienen entidades humanas y no humanas y el proceso continuo de transformación o traducción de las relaciones establecidas entre tales entidades da como resultado una red en continuo cambio; entendida ésta como una malla formada por nudos (actores) enlazados entre sí (relaciones que establecen entre ellos). Estos cambios en las relaciones tienen como consecuencia la aparición, el fortalecimiento, el equilibrio, el debilitamiento y la desaparición de los actores. El sistema de conocimiento Copalred (C permite visualizar el proceso de traducción en las redes tecnocientíficas mediante el análisis dinámico de las mismas.

2. El diagrama estratégico (figura 1), es un diagrama cartesiano que se emplea para clasificar a las subredes estratégicas en función de su rango de centralidad (eje de abscisas) y de su rango de densidad (eje de ordenadas). Según el cuadrante en el que se sitúan, éstas pueden ser: cuadrante n. ${ }^{\circ} 1$, subredes de altas centralidad y densidad (subredes motor de investigación); cuadrante n. ${ }^{\circ}$, subredes de alta centralidad y baja densidad (subredes puente o categorizaciones); cuadrante n. ${ }^{\circ}$, subredes de baja centralidad y alta densidad (subredes especializadas o metodologías), y cuadrante n. ${ }^{\circ}$, subredes de bajas centralidad y densidad (subredes nacientes o en destrucción). Así resulta que las subredes de mayor centralidad y densidad son las subredes mejor situadas en la red y las de mayor pertinencia con el objeto del estudio.

3. En la figura 2, se observan las áreas estratégicas de investigación. Se han obtenido agrupando las subredes estratégicas similares. Cada subred está constituída por términos, los cuales pueden ser palabras clave, investigadores o revistas (en la figura los términos aparecen nombrados por su número de identificación). Se puede observar la posición que ocupan las diferentes áreas y subredes estratégicas entorno al centroide o isobaricentro del grafo del Componente Principal de la Red.

4. En la figura 3, se observa una imagen 3D del Mapa CERT del Componente Principal de la Red (el mapa real está realizado sobre formato A3). En planimetría se visualiza la similitud entre los términos (proximidad entre ellos) y la centralidad (proximidad al centroide). La agrupación de términos constituye subredes o grupos estratégicos y la agrupación de subredes áreas estratégicas. La mayor o menor cercanía de los términos, de las subredes o de las áreas de investigación al centroide indica su mayor o menor grado de relación con la temática general del estudio ("Investigación sobre áreas protegidas en España"). En altimetría se visualiza, mediante una escala de color de tintas hipsométricas, la importancia absoluta de cada término (suma de su centralidad y de su densidad, 
en valores normalizados). Si sobre el Mapa CERT se indica mediante símbolos de diferente forma y color la importancia estratégica de los términos de las subredes de investigación se obtiene el Mapa de Importancia Estratégica (Mapa I-VECT).

5. En la tabla V en las columnas Departamento, Centro, Grupo y Línea de investigación figuran los datos de los autores obtenidos en la web a la fecha de realización del artículo. 